\title{
1 QTL and drought effects on leaf physiology in lowland Panicum virgatum
}

2 Taylor, Samuel H. ${ }^{1,3^{*}}$, Lowry, David B. ${ }^{1,4}$, Aspinwall, Michael J. ${ }^{1,5}$, Bonnette, Jason E. ${ }^{1}$, Fay, 3 Philip A. ${ }^{2}$, Juenger, Thomas E. ${ }^{1}$

$4{ }^{1}$ Department of Integrative Biology, University of Texas at Austin, Austin TX 78712, USA

$5 \quad{ }^{2}$ USDA-ARS Grassland Soil and Water Research Laboratory, Temple, TX 76502, USA

6 Current Addresses:

$7{ }^{3}$ Departments of Environmental Studies and Biology, Keene State College, Keene, NH 03431

$8 \quad{ }^{4}$ Department of Plant Biology, Michigan State University, East Lansing, MI, 48824

$9{ }^{5}$ Hawkesbury Institute for the Environment, Western Sydney University, Penrith, NSW 2751,

10 Australia

$12{ }^{*}$ Corresponding Author: Samuel Taylor

13 Telephone, +1-512-758-3483; Fax, ; Email, smuel.tylor@gmail.com

\section{Acknowledgements}

16 The authors thank two anonymous reviewers and M.D. Casler for their editorial comments. We

17 wish to thank T.S. Quedensley for assistance with clonal propagation and planting, and A.

18 Asmus for technical assistance; W. Skillern, D. Dillon, L. Taranow, Ca. Timmerman, Co.

19 Timmerman, A. Hiers, L. Villareal, C. Lee, all students in the Freshman Research Initiative, and

20 E. Worchel helped to collect physiological measurements. John Crutchfield and the staff of

21 Brackenridge Field Labs were invaluable resources, particularly during construction and

22 development of the experimental rainout shelters utilized in the study. This study was funded by 23 an National Science Foundation Plant Genome Research Program grant to TEJ and PAF (NSF

24 IOS-0922457). A United States Department of Agriculture-Agriculture and Food Research

25 Initiative Postdoctoral Fellowship (2011-67012-30696) supported DBL during the time that the

26 experiments were conducted. SHT was supported by Bowdoin College during data analysis and 27 manuscript preparation. 
28 Abstract

29 Switchgrass is a key component of plans to develop sustainable cellulosic ethanol production for

30 bioenergy in the US. We sought quantitative trait loci (QTL) for leaf structure and function,

31 using the Albany full-sib mapping population, an $\mathrm{F}_{1}$ derived from lowland tetraploid parents. We

32 also assessed both genotype $\times$ environment interactions $(\mathrm{G} \times \mathrm{E})$ in response to drought and spatial

33 trends within experimental plots, using the mapping population and check clones drawn from the

34 parent cultivars. Phenotypes for leaf structure and physiological performance were determined

35 under well watered conditions in two consecutive years, and we applied drought to one of two

36 replicates to test for $\mathrm{G} \times \mathrm{E}$. Phenotypes for check clones varied with location in our plot and were

37 impacted by drought, but there was limited evidence of $\mathrm{G} \times \mathrm{E}$ except in quantum yield ( $\left.\Phi_{\text {PSII }}\right)$.

38 Phenotypes of Albany were also influenced by plant location within our plot, and after correcting

39 for experimental design factors and spatial effects we detected QTL for leaf size, tissue density

40 (LMA), and stomatal conductance $\left(g_{s}\right)$. Clear evidence of $\mathrm{G} \times \mathrm{E}$ was detected at a QTL for

41 intrinsic water use efficiency (iWUE) that was expressed only under drought. Loci influencing

42 physiological traits had small additive effects, showed complex patterns of heritability, and did

43 not co-localize with QTL for morphological traits. These insights into the genetic architecture of

44 leaf structure and function set the stage for consideration of leaf physiological phenotypes as a

45 component of switchgrass improvement for bioenergy purposes.

46

\section{Keywords}

48 switchgrass; Panicum virgatum; photosynthesis; QTL; genotype $\times$ environment; water use

49 efficiency 


\section{Introduction}

51 Concerns about fuel security and greenhouse gas emissions during the last decade led to

52 mandated increases in fuel production from biomass sources in the United States, complemented

53 by promotion of other renewable energy sources and technologies for greenhouse gas capture

54 [1]. In addition to providing a novel domestic energy supply, effective implementation of biofuel production can help to offset $\mathrm{CO}_{2}$ emissions from ubiquitous fossil fuel combustion technologies [2]. However, bioenergy production in the United States competes for space with agricultural and natural ecosystems [3] during a period in which there are increasing concerns about the sustainability of food crop yield increases necessary to feed growing human populations $[4,5]$. It is therefore increasingly important that high efficiency bioenergy crops are developed.

Switchgrass (Panicum virgatum) and switchgrass containing mixtures of native grasses, with their capacity for high productivity and soil carbon storage on marginal lands across the United States, are leading candidates to improve efficiency and reduce pollution linked with current bioenergy production from corn [6-11]. Biologists and agronomists have made rapid progress in developing the resources necessary for improvement of switchgrass as an energy crop $[11,12]$ and have begun to release new high yielding varieties [13]. Most published research aimed at improvement of switchgrass has focussed on yield and biomass characteristics $[6,14,15]$. Among plant physiologists, however, there is an understanding that resource use efficiencies are important when considering biomass yield in energy crops [16-18]. We therefore addressed the genetic architecture of leaf-level phenotypes in switchgrass, including water use efficiency.

In the study of leaf physiology, technical advances over the last forty years have seen the development of field portable systems for measuring photosynthetic performance [19-20] and detailed models that allow us to scale up predictions of environmental responses at the leaf scale to canopies and even global vegetation models [21]. Ecological datasets have also shown that plant leaves demonstrate adaptations to habitat driven by trade-offs linking leaf lifespan with photosynthetic efficiency $[22,23]$. One important trade off central to leaf function in most plants is that between carbon assimilation and water loss: carbon uptake requires that stomata be open, risking desiccation of photosynthetic tissues because of inevitable water loss through transpiration [24]. Both photosynthetic performance and rates of water loss are strongly driven 
79 by abiotic factors $[25,26]$ but leaf function is also maintained by structural and biochemical

80 differences that are linked with genetic variation among individuals [27-29]. From a crop

81 improvement perspective it is important to note that natural selection has acted to oppose maximization of canopy and stand level photosynthetic efficiency because of conflicts with competitive interactions, leaving opportunities for intervention to improve efficiency in plant productivity [5]. It is also clear that we do not yet understand how adaptations evident within and among plant communities map to intraspecific variation that underpins evolutionary lability of and their plasticity is therefore essential, both to help address gaps in our basic understanding of plant performance and to inform approaches to the improvement of efficiency in plant biomass production.

In switchgrass, intraspecific variation in photosynthetic performance has been studied for decades $[32,33]$. Classic physiological studies addressed differences in leaf performance between ecologically differentiated upland and lowland switchgrass populations with distinct vegetative phenotypes and ploidy levels $[32,34]$. Evidence for local adaptation $[35,36]$ has also led to more recent experiments focussed on inter-population variation in productivity and physiological performance [6, 33, 37-40]. Results from these experiments support differences in seasonal patterns of photosynthetic performance that complement adaptive variation in phenology $[33,39,40]$. Our recent, detailed studies of leaf physiological traits among ecotypic variants of switchgrass suggest that they are genetically determined and linked with local adaptation in the species [39]. Here, we focus instead on genetic variability in leaf phenotypes of lowland populations. This variation is important because it provides the raw materials for local adaptation among populations and because it will influence the outcome of crop improvement strategies based on lowland germplasm.

Switchgrass breeding for bioenergy purposes is being facilitated by existing genetic resources and cutting edge technologies for genomics and transgenics $[12,41]$ including the development of genetic maps [42-47]. QTL mapping is an important component of switchgrass improvement programs both because it identifies the native genetic variability available to breeders and because information from QTL studies can be utilized directly in marker assisted selection approaches. The first published QTL studies using switchgrass have focused on 
109 phenotypes for biomass, morphology, and flowering time [48-50]. Though a number of

110 switchgrass mapping populations have now been produced, the first high density linkage map 111 was developed for the Albany population (ALB, developed in Albany, CA [47]). A single 112 generation $F_{1}$, the ALB population allows detection of QTL for genetic variation segregating 113 within parents selected from two highly productive lowland cultivars: Alamo-A4 (male), and 114 Kanlow-K5 (female); we have already demonstrated that there is segregating variation in ALB 115 for leaf coloration, and for agronomic traits including biomass yield [49].

116 We asked whether the lowland switchgrass parents of ALB and two check clones drawn 117 from the parent cultivars show genetic variation in leaf physiology and structure. We also asked 118 whether genetic variation for leaf phenotypic responses to drought $(\mathrm{G} \times \mathrm{E})$ could be detected in 119 lowland switchgrass, and whether phenotypes were plastic in response to local abiotic gradients 120 within our experiment. We mapped QTL for leaf phenotypes under well watered conditions 121 during two growing seasons, and tested for $\mathrm{G} \times \mathrm{E}$ by applying a controlled drought treatment 122 under a rain-out shelter.

\section{Rain-out shelter and plant material}

To facilitate drought experiments our work was conducted under a rain-out shelter (Windjammer Cold Frame, International Greenhouse Company, Danville, IL, USA) located at the University of Texas Brackenridge Field Laboratory in Austin, TX (N 30.2845, W -97.7809) [49]. The footprint of the shelter's steel frame is $18.3 \times 73 \mathrm{~m}$, and the shelter is covered with a clear 240 $\mu$ m polyethylene roof that reduces photosynthetically active radiation by $\sim 10 \%$. The walls $(2.1$ meters) and eaves (4.2 meters) of the shelter are open to allow free air circulation.

To allow paired comparisons of droughted and well watered plants we installed an irrigation system designed by Charles Swanson, Texas A\&M University that allowed independent control of watering in odd and even rows in our experiment. We inserted $3.2 \mathrm{~mm}$ thick hollow plastic sheets (Regal Plastics, Austin, TX) to a depth of $1.2 \mathrm{~m}$, roughly every $2.1 \mathrm{~m}$ along the length of the shelter, providing 34 isolated rows, each of which was irrigated by three parallel strands of drip tape (T-Tape, John Deere; internal diameter $10 \mathrm{~mm}$, flow rate $4.16 \mathrm{~m}^{3}$ 
$138 \mathrm{~m}^{-1}$, drippers $0.42 \mathrm{~m}$ apart). Drip tapes ran the length of each row and were separated by $0.42 \mathrm{~m}$. 139 Pressure regulators maintained pressure below $69 \mathrm{kPa}$, and solenoid valves allowed independent 140 application of water to odd and even rows.

141 Sixteen plants were positioned in each of the 34 rows in our experiment, with roughly 0.9 $142 \mathrm{~m}$ spacing between them. Plants on the perimeter, the first and last row in the field and plants at 143 the ends of other rows, were switchgrass plants from a variety of cultivars and were not 144 measured during experiments: their purpose was to minimize edge effects. Interior plants (14 145 plants $\times 32$ rows $=448$ plants) were two independently randomised replicates of 192 lines from 146 ALB (384 plants) respectively placed into odd and even rows, and 32 clonal replicates of both 147 Kanlow-398209 and Alamo-AP13 (64 plants). Alamo-AP13 and Kanlow-398209 are not the 148 parental lines for ALB (male, Alamo-A4; female, Kanlow-K5), but we incorporated them in our 149 experiment as checks to help identify environmental gradients under the shelter influencing 150 phenotypes. One plant from each of these two clones was planted in every row in the experiment 151 at randomised positions.

The ALB population was shipped to Austin in the summer of 2010. It was divided to 153 produce two clonal replicates of the 192 lines, which were grown in pots until planting during 154 the third week of October 2010. As described, one replicate was planted in odd numbered rows 155 and the other in even numbered rows. During establishment water was applied using a hose twice 156 a week from planting until late November, then once a week until our irrigation system was completed in early March 2011. Odd numbered rows were well watered except during a drought treatment in July 2011. Even numbered rows were continuously watered during growing seasons.

159 Growing season irrigation in the even rows supplied $90 \%$ of expected plant water requirements 160 [49].

\section{Phenotyping}

163 Leaf traits were measured in three large experiments over the course of two years. Experiment A 164 was carried out in the first year of growth $\left(12^{\text {th }}-15^{\text {th }}\right.$ July 2011$)$, with the aim of providing a 165 baseline experiment in which all plants were well watered. Experiment B closely followed 166 Experiment A with the aim of detecting QTL demonstrating G×E: the odd replicate of ALB was 
allowed to dry down, the even remained watered, and physiological performance was measured over the $26^{\text {th }}-29^{\text {th }}$ July 2011 . Finally, in Experiment C (22 $-25^{\text {th }}$ May 2012) we aimed to detect QTL in well watered second year plants early in the growing season.

\section{Experiment A: baseline measurements}

Our aim in this experiment was to obtain baseline measurements prior to drought, thus $\sim 33 \mathrm{~mm}$ of water was added to the entire experiment on the evening of the 10th, followed by an additional $\sim 8-12 \mathrm{~mm}$ on the evenings of the 12th, 13th and 14th of July. We sampled the 32 rows of plants in four blocks of eight adjacent rows, each block being randomly allocated to a day within the experiment. Pre-dawn, we sheathed a youngest fully emerged leaf blade on each plant in a plastic bag and immediately detached it above the ligule using sharp scissors. We stored the bagged leaf blades in a cool box and refrigerator, before scanning them (Epson Perfection V37, Epson America, Long Beach, CA) and placing them into coin envelopes for drying. We determined leaf areas using Image J software [51], and, after drying the leaves for at least $48 \mathrm{~h}$ at $65^{\circ} \mathrm{C}$, determined their dry mass using an analytical balance (AB104-S, Mettler-Toledo, LLC, Columbus $\mathrm{OH}$ ). We calculated leaf mass per area (LMA) as dry mass/leaf area. Within each sampling block we randomly assigned two rows to each of four LI-6400XT portable photosynthesis systems (LI-COR Inc., Lincoln, NE) equipped with integrated modulated fluorometers (LI-6400-40), and between 11 am and 2:30 pm we used either one, or two (as necessary to fill the gas exchange cuvette) young fully emerged leaves to determine leaf gas exchange (net $\mathrm{CO}_{2}$ assimilation, $A$; stomatal conductance to water, $g_{s}$; and intrinsic water use efficiency, $\left.\mathrm{iWUE}=A / g_{s}\right)$ and chlorophyll fluorescence (effective quantum yield, $\Phi_{\mathrm{PSII}}=$ $\left(\mathrm{F}_{\mathrm{m}}{ }^{\prime}-\mathrm{F}_{\mathrm{s}}\right) / \mathrm{F}_{\mathrm{m}}$; ; efficiency of energy harvesting by oxidized PSII reaction centers in the light, $\mathrm{F}_{\mathrm{v}}{ }^{\prime} / \mathrm{F}_{\mathrm{m}}{ }^{\prime}=\left(\mathrm{F}_{\mathrm{m}}{ }^{\prime}-\mathrm{F}_{\mathrm{o}}{ }^{\prime}\right) / \mathrm{F}_{\mathrm{m}}{ }^{\prime}$; and photochemical quenching, $\left.\mathrm{qP}_{\mathrm{p}}=\left(\mathrm{F}_{\mathrm{m}}{ }^{\prime}-\mathrm{F}_{\mathrm{s}}\right) /\left(\mathrm{F}_{\mathrm{m}}{ }^{\prime}-\mathrm{F}_{\mathrm{o}}{ }^{\prime}\right)\right)$; we measured flag leaves (subtending emerging or fully emerged flowers) in all but three cases. Based on weather station measurements from the site and an initial reading taken before measurements began, we fixed light levels in LI-6400XT cuvettes to match the expected average photosynthetic photon flux density (PPFD) during the measurement period (mean $\pm \mathrm{sd}: 1620 \pm 18 \mu \mathrm{mol} \mathrm{m} \mathrm{m}^{-2} \mathrm{~s}^{-1}$ ). We also fixed block temperatures, resulting in cuvette air temperatures of $37.3 \pm 1.38{ }^{\circ} \mathrm{C}$ 
196 (mean \pm sd). We maintained reference $\mathrm{CO}_{2}$ concentrations in the open system at $410 \mu \mathrm{mol} \mathrm{mol}^{-1}$ using $\mathrm{CO}_{2}$ mixers (LI-6400-01), which resulted in cuvette $\mathrm{CO}_{2}$ concentations of $393 \pm 6.6 \mu \mathrm{mol}$ $198 \mathrm{~mol}^{-1}$ (mean $\left.\pm \mathrm{sd}\right)$. Finally, we did not control relative humidity of incoming air; cuvette values 199 for relative humidity were $54 \pm 12 \%($ mean \pm sd).

\section{Experiment B: drought experiment}

Our aim in Experiment $B$ was to investigate $\mathrm{G} \times \mathrm{E}$ in leaf physiological performance as responses to drought. We imposed drought on odd rows and maintained watering of even rows. Drought was imposed by restricting watering, which allowed plants to deplete soil moisture. All rows were watered with $\sim 63 \mathrm{~mm}$ on the $17^{\text {th }}$ and $18^{\text {th }}$ of July 2011 . Subsequently, only the even rows were irrigated with $\sim 34 \mathrm{~mm}$ on July $23^{\text {rd }}$, and $\sim 21 \mathrm{~mm}$ on both the $26^{\text {th }}$ and $28^{\text {th }}$ of July. We used volumetric water content (VWC, \%) in the top $20 \mathrm{~cm}$ of soil, measured at four evenly spaced positions along each row using a Hydrosense soil moisture probe (Campbell Scientific, Inc., Logan, UT), to determine when to initiate phenotyping and to account for variable rates of soil drying across our site. We began phenotyping on July $26^{\text {th }}$, when VWC in the even rows of the experiment averaged $21 \pm 7.2 \%$ (mean $\pm \mathrm{sd}, \mathrm{N}=64)$ compared with $5 \pm 2 \%$ in odd rows, consistent with odd-row soil water potentials below wilting point (Fig. S1). We began phenotyping in pairs of adjacent odd and even rows where average soil moisture was lowest, giving rows with higher soil moisture contents additional time to dry down. We measured eight rows of plants per day for four days, pairs of adjacent odd and even rows being randomly allocated to one of four LI-6400XT photosynthesis systems. We completed photosynthesis measurements as in Experiment $A$ then, at around 2:30 pm each day, selected an independent set of leaves for determination of midday water potentials $\left(\Psi_{\mathrm{m}}\right)$. We sheathed leaf blades in Ziploc bags (containing damp paper towels to halt transpiration), immediately excised them, stored them in cool boxes, and removed them to the on-site laboratory for measurement using one of two Scholander-type pressure bombs (PMS-1000, PMS Instrument Company, Albany, OR) attached to cylinders of compressed nitrogen. 


\section{Experiment $C$ : minimizing day effects}

225 Because preliminary analyses of Experiment A and B did not show much evidence for genetic 226 effects, Experiment C was designed to determine whether QTL for physiological traits could be detected in second year plants early during the growing season. We had observed larger differences between the check clones Alamo-AP13 and Kanlow-398209 in preliminary measurements made in June 2011 (unpublished data) than in Experiments A and B during July. Evidence for spatial and temporal effects in our 2011 measurements also suggested a need for a stratified, rather than random, sampling approach. We therefore carried out Experiment $\mathrm{C}$ in May 2012, following tiller emergence in February and March. To minimize temporal effects within each mapping population we measured the even rows on May $22^{\text {nd }}$ and $23^{\text {rd }}$, and the odd rows on May $24^{\text {th }}$ and $25^{\text {th }}$. We measured eight rows per day, two from every quarter of the length of the shelter. Rows were randomly assigned to four LI-6400XT photosynthesis systems paired with two Scholander pressure bombs. We measured pre-dawn water potential $\left(\Psi_{\mathrm{pd}}\right)$ using one leaf blade from each plant, which was sheathed in plastic, excised using sharp scissors, and measured at the field site within 30 minutes. Gas exchange measurements always used two leaves, and were made $2 \min 30 \mathrm{~s}$ after closing the cuvette, a period determined to be adequate for reequilibration of gas concentrations. (The fluorometer function of one LI-6400-40 malfunctioned, so we discarded chlorophyll fluorometry data from this experiment.). We standardized for phenology wherever possible by using youngest fully emerged leaves from vegetative tillers or tillers yet to reach anthesis: $93 \%$ of measurements were made using pairs of tillers yet to reach anthesis. We matched cuvette conditions (mean $\pm \mathrm{sd}$ : PPFD, $1203 \pm 4.5 \mu \mathrm{mol} \mathrm{m} \mathrm{m}^{-2} \mathrm{~s}^{-1}$; air temperature, $31 \pm 0.27^{\circ} \mathrm{C}$ ) to expected light and temperature conditions as in Experiments $\mathrm{A}$ and B. To reduce variability in the driving force for transpiration that underpins measurements of $g_{s}$ we controlled water concentration in the reference channel at $32.9 \pm 0.97 \mathrm{mmol} \mathrm{mol}^{-1}$ (mean $\pm \mathrm{sd}$ ).

252 Leaf Area Meter (LI-COR Inc.). Leaves were then dried and LMA was calculated as above. 
Because pre-dawn water potentials showed limited variability and a highly non-normal distribution they were not analysed as a quantitative trait, but we did use them to standardize midday water potentials by calculating the hydrodynamic gradient $\left(\Delta \Psi=\Psi_{\mathrm{m}}-\Psi_{\mathrm{pd}}\right)$.

\section{Data processing}

Rapidly made measurements of physiological traits usually require quality control for unusual values linked with operator error. We therefore inspected bivariate plots of leaf traits and removed clear outliers prior to statistical analysis. For Experiments A and B we removed measurements from five individuals with leaf intercellular $\mathrm{CO}_{2}$ concentrations $\left(c_{i}\right)$ outside a physiologically reasonable range of $0-400 \mu \mathrm{mol} \mathrm{mol}^{-1}$. In addition we removed one individual with $\Psi_{\mathrm{m}}=-4.65 \mathrm{MPa}$ (33\% greater than the highest retained value), and two individuals with $\Phi_{\text {PSII }}>0.37$ ( $>21 \%$ greater than the highest retained value) from the Experiment B dataset. There were no similarly unique values measured in Experiment $C$, but on the basis of substantial deviations from linear relationships between traits we excluded data for $g_{s}$ from three plants where values were outside of the usual range given $A$ (which strongly influenced iWUE), and one plant where leaf area was unusual given leaf mass (which strongly influences LMA). To ensure that analyses from all experiments were comparable we further removed data for clones that were not duplicated within the field or that were missing from any of Experiments A, B, or C. After these exclusions, data was retained for 165 of the original 192 ALB genotypes (86\%), 30 clonal replicates of Kanlow-398209, and 32 clonal replicates of Alamo-AP13.

\section{Effects of genotype and environment on phenotypes}

Among the ALB we evaluated the relative importance of environmental gradients for different phenotypes and corrected for the effects of experimental factors using generalized least squares models ( $g l s$ function in nlme 3.1-120, with glsControl(opt="optim"); [52]). For Experiments A and $B$, using maximum likelihood as a criterion, we fit the model $X_{i j}=\alpha_{i}+\theta_{j}+\gamma_{k}+\varepsilon_{i j k}$, where $\alpha_{i}$ are the odd and even replicates, $\theta_{\mathrm{j}}$ a fixed effect of the day within the experiment, and, where appropriate, $\gamma_{\mathrm{k}}$ is a fixed effect of equipment used in the experiment (LI-6400XT machines or Scholander pressure bombs depending on the trait). For Experiment $\mathrm{C}$, odd and even rows were 
282 fit using separate models because they had been measured consecutively. To determine the significance of spatial effects we used likelihood ratio tests to compare models fit using restricted maximum likelihood that either assumed a normal error distribution or corrected for correlations due to distances among plants. Within-plot spatial correlations were modelled as a component of measurement error, $\varepsilon_{\mathrm{ijk}}$, as $\sigma^{2} \times \gamma(r, d)$, where if $r>0, \gamma(r, d)=(1-n) \times\left(1-1.5(r / d)+0.5(r / d)^{3}\right)$, and if $r \geq d, \gamma(r, d)=0: r$, is distance; $d$, a range; $n$, a nugget (spherical autocorrelation structure [52]). Phenotypes corrected for both experimental factors and spatial patterning were extracted

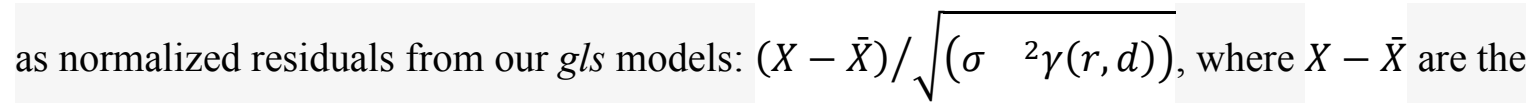
raw residuals (observed - fitted).

Because we had only two replicates of the ALB population, we indexed the degree of genetic determination among ALB genotypes as repeatability, i.e., the Pearson correlation coefficient for the clonal replicates.

Owing to greater replication we were able to use $g l s$ to determine effects of genotype $(\mathrm{G})$, environment $(E)$, genotype $\times$ environment interactions $(G \times E)$ and plot-scale spatial trends for Alamo-AP13 and Kanlow-398209. We fit the fixed effects model $X_{i j}=\alpha_{i}+\beta_{j}+\alpha_{i} \beta_{j}+\varepsilon_{i j}$, using maximum likelihood: $X_{\mathrm{ij}}$ are phenotypes, $\alpha_{\mathrm{i}}$ are the two genotypes; $\beta_{\mathrm{j}}$ are the odd and even rows in the experimental design; $\alpha_{\mathrm{i}} \beta_{\mathrm{j}}$ interaction terms; and $\varepsilon_{\mathrm{ij}}$ the residual. Because we did not fit effects of days and observers in these models we were able to fit the same model for all three experiments, but note that $\beta_{\mathrm{j}}$ in Experiment $\mathrm{C}$ incorporated day effects that were a component of $\varepsilon_{\mathrm{ij}}$ in Experiments A and B. Significance of fixed effects and the spherical autocorrelation structure were tested as for ALB. Predicted means for Alamo-AP13 and Kanlow-398209 in odd and even rows were obtained as linear combinations of coefficients and corresponding standard errors using the package contrast [53].

\section{QTL mapping}

We implemented QTL mapping using the R package qtl [54]. Prior to QTL mapping we constructed our outbred linkage map using OneMap [55] and raw marker genotyping data available from an original mapping study that used ALB [47] (Details of map construction were given in a previous publication [49]). Our primary analysis used scanone to implement Haley- 
311 Knott regression, but we also carried out non-parametric analyses to account for observations of 312 heteroskedasticity, skewed distributions and occasional outliers (Tables S1 \& S2). Thresholds for 313 rejection of the null hypothesis of no QTL at $\mathrm{P}<0.05$, and $\mathrm{P}<0.1$ were estimated using 1000 314 permutations. We used makeqtl and fitqtl to estimate 1.5 LOD drop confidence intervals and percent variance explained. We mapped using the odd and even replicates separately for all three experiments for consistency, since in Experiment B we fit QTL separately for watered and droughted rows. We also used a post-hoc analysis to determine whether QTL-linked markers showed significant effects of genotype, environment (odd versus even replicate) and/or $\mathrm{G} \times \mathrm{E}$. Because many QTL-linked markers were not fully informative our post-hoc analysis used 500 imputed genotype draws from simgeno to repeat ANOVA analyses, and we report summaries of the distribution of P-values from these 500 ANOVA. We also used the 500 draw set of imputed genotypes to estimate genotype level effects for QTL using effectplot and to link phenotypes with genotype assignments using plotpxg.

\section{Results}

\section{Effects of genotype and environment: Alamo-AP13 and Kanlow-398209}

We found few significant differences between the Alamo-AP13 and Kanlow-398209 genotypes (Fig. 1; Table 1). Among 24 phenotypes significant effects of genotype (Table 1) were found for leaf area and LMA in Experiments A (Fig. 1h \& i) and C (Fig. 1w \& x), leaf mass in Experiment A (Fig. 1g), and $F_{v}{ }^{\prime} / F_{m}{ }^{\prime}$ in Experiments $A$ and B (Fig. 1e \& n). Differences between the genotypes in $A$ and $g_{s}$ were only marginally non-significant $(0.05<\mathrm{P}<0.058)$ in Experiment $\mathrm{C}$ (Table 1; Fig 1q \& s).

The drought treatment imposed in Experiment B (Fig. 1j-p) decreased $\Psi_{\mathrm{m}}$ (Fig. 1p), gas exchange $\left(A, g_{s} ;\right.$ Fig $\left.1 \mathrm{j} \& \mathrm{k}\right)$, and photosynthetic performance $\left(\Phi_{\mathrm{PSII}}, \mathrm{F}_{\mathrm{v}}{ }^{\prime} / \mathrm{F}_{\mathrm{m}}{ }^{\prime}, \mathrm{qP}_{\mathrm{P}} ;\right.$ Fig. $\left.1 \mathrm{~m}-\mathrm{o}\right)$ in both Alamo-AP13 and Kanlow-398209 (Table 1). The only trait for which no significant effect of drought was detected was iWUE (Fig. 11), and only one trait showed significant G $\times \mathrm{E}\left(\Phi_{\mathrm{PSII}}\right.$; Fig. $1 \mathrm{~m}$ ); however, decreases in $A, g_{s}, \Phi_{\mathrm{PSII}}$, and qP were usually greater for Alamo-AP13 than Kanlow-398209 (Fig. 1). The marginally significant $\mathrm{G} \times \mathrm{E}$ effect on $\Phi_{\mathrm{PSII}}(\mathrm{P}=0.046)$ was detected against a background of marginal $\mathrm{G} \times \mathrm{E}$ effects for other traits; only qP showed $\mathrm{P}<0.1$ 
340 for $\mathrm{G} \times \mathrm{E}$ in Experiment $\mathrm{A}$ but $A, g_{s}$ and qP all showed $\mathrm{P}<0.082$ in Experiment $\mathrm{B}$ (Table 2).

341 Differences between the odd and even replicates were also detected for four phenotypes: $A, g_{s}$, $342 \Delta \Psi$, and LMA (Fig 1q, $r, u$, and $\mathrm{x}$ ), in Experiment $\mathrm{C}$ (Table 1), probably as a result of consecutive phenotyping of the odd and even rows rather than chronic effects of the previous year's drought treatment.

Tests of spatial effects supported plasticity of Alamo-AP13 and Kanlow-398209 in response to location under the shelter for 8 of the 24 phenotypes (Table 2). The traits linked with significant spatial patterns were: leaf area, and leaf mass, in Experiment A; A, $\Phi_{\mathrm{PSII}}, \mathrm{q}_{\mathrm{P}}$, and $\Psi_{\mathrm{m}}$, in Experiment B; then leaf area, and LMA, in Experiment C.

\section{Effects of genotype and environment: $A L B$}

Correlations between clonal replicates (repeatabilities, Pearson's $\rho$ ) indicate the importance of genetic effects over environmental effects and measurement error. In ALB we found that repeatabilities tended to be greater for leaf structural traits $(0.12$ to 0.35$)$ than physiological traits ( -0.05 to 0.17 : negative values were not significantly different from 0 ; Table 2 ). Importantly, when we corrected for experimental factors (additive effects of odd-even, day of measurement, and observer, as well as spatial autocorrelation, Table 4) by calculating $\rho$ among normalized residuals we found that $\rho$ increased for 20 of 24 phenotypes, and was statistically significant $(\mathrm{P}<$ 0.05 ) for 13 phenotypes compared with only seven significant tests using the raw data (Table 2).

Repeatabilities were not markedly different in Experiment B compared with Experiments A and C (Table 2), suggesting that additive genetic differences were comparable under well watered conditions and drought. As expected, drought significantly decreased values for all photosynthetic performance phenotypes and $\Psi_{\mathrm{m}}$ (Fig. 2j-p). Drought had smaller impacts on iWUE (8\% decrease; Fig. 21) and $\mathrm{F}_{\mathrm{v}}{ }^{\prime} / \mathrm{F}_{\mathrm{m}}{ }^{\prime}$ (6\% decrease; Fig. $2 \mathrm{n}$ ) than other phenotypes, which showed decreases ranging from 36\% (qp; Fig. 2o) to 64\% ( $g_{s}$; Fig. 2k). Significant differences between odd and even rows were also observed for two phenotypes in Experiment A (Table 3), but these were linked with very small effects: $+0.03 \%, \mathrm{~F}_{\mathrm{v}}{ }^{\prime} / \mathrm{F}_{\mathrm{m}}{ }^{\prime} ;-0.5 \%$ iWUE (Fig. $2 \mathrm{e} \& \mathrm{c}$ ). We did not directly compare the odd and even replicates in Experiment $\mathrm{C}$ because odd-even comparisons were conflated with day effects. 
By explicitly accounting for spatial effects as a component of error we significantly improved model inference for 53\% of phenotypes from ALB (17/32 tests; Table 3), a greater frequency than for Alamo-AP13 and Kanlow-398209 (33\%, 8/24 tests; Table 1). This difference between the mapping population and the clonal lines likely reflects their different densities within the experiment (Alamo-AP13 and Kanlow-398209 filled 26\% and ALB 74\% of the regularly spaced planting) and suggests that spatial effects on phenotypes acted at relatively fine scales $(\sim 0-5 \mathrm{~m})$ within our plot. Because we measured different suites of traits in each of our three experiments it is difficult to assess how consistent spatial effects were for individual phenotypes, but of the phenotypes measured in both 2011 and 2012, leaf areas (Experiments A \& C) and leaf water status ( $\Psi_{\mathrm{m}}$, Experiments B \& $\mathrm{C} ; \Delta \Psi$, Experiment $\mathrm{C}$ ) showed spatial patterning in both years (Table 3$)$. By contrast, leaf gas exchange $\left(A, g_{s}\right.$, iWUE) and leaf mass showed significant spatial variability in 2011 but not 2012, and LMA showed significant spatial effects only in 2012 (Table 3).

\section{$Q T L$}

Using normalized residuals we detected nine QTL with $\mathrm{P}<0.1$, five of which were significant with $\mathrm{P}<0.05$ (Fig. 3; Table 4). QTL for LMA (Experiment A odd replicate only, LG 5b, LOD = 5.14) and leaf mass (Experiment $\mathrm{C}$ odd and even replicates, LG $1 \mathrm{~b}, \mathrm{LOD} \geq 5.25$ ), both structural traits, were most strongly supported. The next most strongly supported QTL was for iWUE (Experiment B odd replicate only, LG 9a, LOD = 4.66) and the only other QTL with $\mathrm{P}<0.05$ was for $\mathrm{q}_{\mathrm{P}}($ Experiment A even rows only, LG 5b, LOD = 4.62). We detected four QTL in the marginal range $(0.05<\mathrm{P}<0.1)$, two for $g_{s}$ (Experiment A even replicate only, LG $2 \mathrm{~b}$, $\mathrm{LOD}=4.06$; Experiment B even replicate only, $\mathrm{LG} 3 \mathrm{a}, \mathrm{LOD}=3.93$ ), a pair of co-localising QTL for $\Phi_{\mathrm{PSII}}$ and $\mathrm{q}_{\mathrm{P}}$ (Experiment A even replicate only, LG 5b, LOD $\geq 4$ ), and a QTL for leaf area that co-localised with the more strongly supported QTL for leaf mass (Experiment C even replicate only, LG 1b, LOD = 4.07). Consistent with LOD scores and corresponding P-values, the percentage of additive variance explained by QTL (Table 4) was greatest for leaf structure phenotypes (10.8-14.1\%) and less than $10.8 \%$ for all of the physiological phenotypes except 


\section{$G \times E$ and parental effects at $Q T L$}

400 We found limited evidence to support $\mathrm{G} \times \mathrm{E}$ in check clones, showed that repeatabilities were 401 improved for a number of traits when correcting for experimental effects, and found that the 402 majority of QTL were detectable in one or other of the two replicates of ALB. We therefore 403 tested for genotype, environment (even versus odd replicates), and $\mathrm{G} \times \mathrm{E}$ effects at each of our 404 QTL using marker regression. We had also been surprised to find a QTL for iWUE in 405 Experiment B because repeatabilities for that phenotype were particularly low. So, we also 406 aimed to determine whether that QTL was linked with significant $\mathrm{G} \times \mathrm{E}$, which could explain low 407 scores for repeatability. We accounted for the effect of uncertainty in genotyping at marker and 408 pseudomarker locations by repeating ANOVA tests of G, E and $\mathrm{G} \times \mathrm{E}$ for 500 imputed genotype 409 sets and report means and percentiles of P-values we obtained.

410 Our analysis showed that using normalized residuals fully corrected for any offsets 411 between the odd and even replicates in our experiments ( $E$, mean $P \geq 0.365$; Table 5). We also 412 found that there was strong support for additive effects of genotype underpinning QTL for the 413 structural traits LMA and leaf mass ( $G$, mean $P<0.0001$; $\mathrm{G} \times \mathrm{E}$, mean $\mathrm{P} \geq 0.207$; Table 5), while 414 QTL for physiological traits showed mixed outcomes. Two co-localizing QTL on LG 5b, for $415 \Phi_{\text {PSII }}$ and $\mathrm{q}_{\mathrm{P}}$, showed no significant effects at the marker level (mean $\mathrm{P} \geq 0.168$; Table 5). 416 Although some imputed genotype sets for these two QTL did support significant effects of G ( $5^{\text {th }}$ 417 percentile $\mathrm{P} \leq 0.029)$ some also supported significant $\mathrm{G} \times \mathrm{E}\left(5^{\text {th }}\right.$ percentile $\mathrm{P} \leq 0.021$; Table 5$)$ and 418 these two QTL were not supported by alternative mapping approaches using raw trait values 419 and/or non-parametric techniques (Tables S1 and S2). At both markers linked with QTL for $g_{s}$ 420 additive effects of genotype were significant (mean $\mathrm{P} \leq 0.018$ ); however, while sww2747 on LG 421 3a showed no strong support for significant $\mathrm{G} \times \mathrm{E}$ (mean $\mathrm{P}=0.071$; Table 5), despite being 422 detected in the absence of drought in Experiment A sww 1517 on LG $2 \mathrm{~b}$ did show significant $423 \mathrm{G} \times \mathrm{E}$ (mean $\mathrm{P}=0.047$; Table 6). The strongly supported QTL for iWUE (LG 9a, Experiment B) 424 also showed significant $\mathrm{G} \times \mathrm{E}$ (mean $\mathrm{P}=0.005$; Table 5); it was detected only under drought. $425 \quad$ Segregating variation from both parents contributed to QTL and G×E effects. Among 426 QTL that our ANOVA tests supported as primarily additive (Table 5, Fig. 4): the QTL for odd 
mass and leaf area on LG $1 \mathrm{~b}$ segregated from Kanlow-K5 (Fig. 4a-f), while markers for LMA on LG 5b (sww332c) and $g_{s}$ on LG3a (sww2747) showed less clear cut phenotype-genotype linkages (Fig. 4g-j). These QTL for LMA and $g_{s}$ showed segregation from Alamo-A4 that was stronger in combination with one Kanlow-K5 allele than with the other (Fig. 4g-j; at least a small fraction of genotype calls at both of these markers provided support for marginal $\mathrm{G} \times \mathrm{E}$ effects: $5^{\text {th }}$ percentile $\mathrm{P} \leq 0.062$ ). Significant $\mathrm{G} \times \mathrm{E}$ for $g_{s}$ at sww1517 on $\mathrm{LG} 2 \mathrm{~b}$ was linked with among genotype effects in the even replicate (Fig. 5a) where the QTL was detected, and no differences among genotypes in the odd replicate (Fig. 5b). For individuals in the even replicate with the second Kanlow-K5 allele at sww1517, values of $g_{s}$ were smaller, but there was also a clear pattern of reduced variation in $g_{s}$ among individuals containing one of the Alamo-A4 alleles (Fig. $5 a-b)$. This heteroskedasticity in phenotypic values for $g_{s}$ had no obvious explanation arising from our experimental design, and was challenging from a data analysis perspective: nonparametric analysis did not support the QTL (Table S2). Finally, G×E in iWUE at nfsg107 (LG 9a), detected when drought was applied in Experiment B, clearly arose through segregation from the Alamo-A4 parent: no effect was observed under well watered conditions (Fig. 5c) and differences in iWUE under drought arose between individuals carrying different alleles from Alamo-A4 (Fig 5d).

\section{Discussion}

Using the ALB lowland switchgrass mapping population we found evidence for QTL influencing leaf structure and performance. Repeatabilities tended to be greater for leaf structural phenotypes than for leaf performance phenotypes, and we located robust QTL for leaf mass on LG $1 \mathrm{~b}$ and tissue density on LG 5b. In check clones, comparisons between droughted and well watered plants provided only limited evidence for $\mathrm{G} \times \mathrm{E}$, but $1 / 3$ phenotypes showed spatial variation indicating plasticity in response to abiotic gradients. After correcting for spatial effects on ALB we found a QTL on LG 9a that influenced iWUE and was expressed only in response to drought, further demonstrating $\mathrm{G} \times \mathrm{E}$. This evidence for heritable variation and $\mathrm{G} \times \mathrm{E}$ gives insights into the genetic architecture underpinning leaf performance and suggests that leaf phenotypes should be considered as responsive to selection implemented for crop improvement. In addition to evidence 
for plasticity linked with spatial variation in our plots, significant variability in leaf phenotypes linked with observers and days within experiments emphasized the responsiveness of leaf phenotypes to abiotic drivers, which presents a major challenge for large scale phenotyping of physiological traits.

\section{$Q T L$}

Of the QTL we detected, those for leaf size on LG $1 \mathrm{~b}$ and LMA on LG $5 \mathrm{~b}$ were the most strongly supported. The QTL on LG 1b co-localizes with QTL for base tiller width, internode width and $4^{\text {th }}$ leaf length and area that we detected in parallel experiments using ALB [49]. It was a result of segregating variation in Kanlow-K5, in a region of the genome that is covered by maps for both parents $[42,47]$. By contrast, the QTL we detected for LMA at $146 \mathrm{cM}$ on LG 5b is novel, and segregation from Alamo-A4 was implicit in its location: in the original male and female maps for ALB that our map is derived from no information was available for the Kanlow$\mathrm{K} 5$ (female) parent beyond $84 \mathrm{cM}$ of LG 5b [47]. Interestingly, the tip of LG 5b is also not covered in the NF $\times$ GA map [57], more recent genotyping-by-sequencing maps for ALB [42], or a novel four-way cross that incorporates the Alamo-AP13 genotype as a male parent [45]. These results suggest that there may be a low level of polymorphism in the genome of cv. Alamo individuals adjacent to the QTL for LMA, but we also note that a QTL for SLA (1/LMA) segregating in the AP13 $\times$ Dacotah parent of the novel four-way cross was located on LG $5 b$ within $50 \mathrm{cM}(100-110 \mathrm{cM})$ of the QTL we found in ALB [45].

The QTL we detected for iWUE on LG 9a was also linked with segregation in Alamo$\mathrm{A} 4$, and falls within a region covered by the Kanlow map. Given the evidence for $\mathrm{G} \times \mathrm{E}$ at this QTL it is interesting that our confidence intervals showed some marginal overlap with QTL for biomass $(25.4$ and $32 \mathrm{cM})$ and plant height $(74 \mathrm{cM})$ previously detected as showing $\mathrm{G} \times \mathrm{E}$ in the Alamo parent of NF $\times$ GA [48]. However, the peak LOD for our iWUE QTL fell outside the confidence regions given for the NF $\times$ GA QTL [48]. Notwithstanding the difficulties of drawing direct comparisons between maps for these crosses, if our QTL for iWUE is associated with a novel genetic element it may be closely linked with loci known to affect biomass and yield in other switchgrass mapping populations. Attempts to improve biomass and yield related traits in 
485 switchgrass through, e.g., marker assisted selection on LG 9a loci might, therefore, result in unintended selection for leaf physiological responses to drought.

We found several additional QTL for physiological traits. Two QTL explained variation 488 in $g_{s}$. Like the QTL for iWUE both of these were originally detected in only one of the two replicates of ALB. In one case a lack of effects in the second replicate drove significant $\mathrm{G} \times \mathrm{E}$ despite similar watering treatments and the QTL, which was linked with heteroskedasticity among genotypes, was not supported in secondary non-parametric QTL analyses. In the other case, similar effects across the two replicates were supported by our marker regression analysis but those effects were small and appeared to be influenced by both parents. The pattern of heritable variation for this second QTL for $g_{s}(\mathrm{sww} 2747)$ is therefore consistent with transgressive segregation. We were unable to confirm patterns of segregation for phenotypes because parental genotypes were not available, but we have previously demonstrated transgressive segregation for several physiological traits in the close relative of switchgrass, Panicum hallii [58]. Determining whether stabilizing selection tends to constrain the evolution of traits showing transgressive segregation may help to determine whether the rarer, more extreme phenotypes arising from crosses could be useful tools for crop improvement.

Another parallel with Panicum hallii is the lack of any evidence for co-localization of physiological QTL with QTL for leaf structural traits [58]. Thus, by contrast with the evidence that QTL for iWUE and biomass yield on LG 9a might show moderate linkage, most aspects of leaf performance seem likely to be genetically independent of leaf structural properties. This result fits with the finding that evolution of leaf phenotypes is generally less constrained by genetic correlation and more constrained by selection against ecologically unfit trait combinations [27]. It has been proposed that there is considerable scope for crop improvement because ecologically unsuitable trait combinations that decrease intraspecific competitive ability, and therefore individual fitness, may improve performance in an agricultural setting [5]. Finally, although our Haley-Knot analysis of normalized residuals identified QTL for $\Phi_{\text {PSII }}$ and qP we found no support for those two QTL using marker regression based on a set of imputed 


\section{Relevance of $G \times E$ in leaf phenotypes}

516 The QTL we located for iWUE (LG 9a) was not detected by approximate tests of additive 517 genetic variation through calculation of repeatabilities, because it was detectable only under 518 drought. One allelic variant segregating from the Alamo-A4 parent was linked with decreased 519 iWUE under drought. Greater iWUE represents greater capacity for net $\mathrm{CO}_{2}$ assimilation $(A)$ 520 relative to stomatal conductance to $\mathrm{H}_{2} \mathrm{O}\left(g_{s}\right)$. Gas exchange measurements from our check clones 521 illustrate how shifts in iWUE can be obtained as a result of subtle differences in the response of $522 A$ and $g_{s}$ to drought: under watered conditions we found that Alamo-AP13 showed higher $A$ and $g_{s}$ than Kanlow-398209, while under drought $A$ and $g_{s}$ were much more similar between the two clonal genotypes and mean values were slightly lower for Alamo-AP13. Higher iWUE was observed for Kanlow-398209 under both droughted and watered conditions, but the difference was exacerbated by drought. When comparing these clonal lines then, the plants with the more conservative photosynthetic strategy exhibited lower $A$ and $g_{s}$ under well watered conditions and were better able to maintain leaf-level efficiency when challenged by drought. A similar pattern may explain differences in performance among ALB lines that depended on the Alamo-A4 allele linked with nfsg107. We found no evidence for QTL influencing $A$ and $g_{s}$ under drought, but plants with lower water use efficiency under drought had similar efficiency under well watered conditions and may have shown differences in gas exchange that were below the detection threshold for QTL in an $\mathrm{F}_{1}$ design. While breeding for improved water use efficiency in crops requires consideration of variation in plant structure and phenology [59] as well as iWUE, the detection of a QTL for iWUE segregating in Alamo germplasm represents a potential step towards genetic approaches to determine the importance of resource use efficiency in switchgrass [60].

Although the 14 to 16 clonal replicates of Alamo-AP13 and Kanlow-398209 are illustrative with respect to iWUE in ALB, they were insufficient to detect significant $\mathrm{G} \times \mathrm{E}$ driven by our drought treatment. Putting this in context, the QTL for iWUE in the lowland ALB was detected with $\mathrm{N} \sim 40$ per genotype. A requirement for large sample sizes, indicating low statistical power, is consistent with the high degrees of similarity among the plants in our experiments, all of which are derived from highly productive southern lowland tetraploid 
544 ecotypes. Greater phenotypic differences are found between northern and southern varieties of 545 switchgrass [6, 33, 37, 39, 61], or between upland and lowland populations [32, 34]. QTL 546 mapping applied to crosses that incorporate this strong genetic differentiation among ecotypes

\section{Experimental design factors influencing leaf phenotypes}

Repeatabilities were lower for photosynthetic and leaf water status phenotypes than for structural traits. The repeatabilities we observed are consistent with values from the literature for the heritability of $A$ and LMA [27]. They are also consistent with the expectation that leaf performance is strongly entrained to variations in light and temperature that occur both within and between days and at seasonal scales $[16,39]$. The intrinsic variability in physiological phenotypes between days drove our decisions to improve spatial and temporal blocking and reduce the number of days spent measuring each replicate of ALB in our Experiment C in 2012. Daytime measurements alone in Experiment C required four LI-6400XT photosynthesis systems and two pressure bombs along with skilled operators, and three or more technical assistants to collect leaf material, determine leaf areas, and package leaf material for subsequent determination of dry mass. That effort was useful because it decreased the frequency of 
573 significant measurement effects on photosynthetic phenotypes. Nonetheless, both ALB and the 574 check clones continued to exhibit plasticity in leaf areas and leaf water status within our plot. 575 The spatial scales of a few meters over which these patterns were observed present considerable challenges for QTL experiments with large perennial grasses that demand distribution of hundreds of genotypes across an experimental site. Despite considerable efforts made during the construction of our rainout shelters to homogenise and evenly distribute topsoil across the site, fine-grained variation in abiotic drivers of performance remained influential. Because adjustment of leaf area is a common mechanism for acclimation in plant hydraulics [56], that both leaf areas and water potentials were repeatedly linked with spatial patterning in our plot suggests heterogeneous water availability may have been a driver for leaf phenotypic plasticity through hydraulic adjustment.

Given strong evidence for within-plot spatial variation in leaf area in both 2011 and 2012, we were surprised to find that within-plot variation in LMA was significant only in 2012. Progress of the switchgrass plants towards establishment may have influenced this pattern, but leaves measured in 2012 were primarily collected from vegetative tillers, rather than the flowering tillers we had sampled in 2011. Repeatabilities for raw values of LMA might therefore have been influenced by the way our sampling strategy represented tiller developmental status. Indeed, measurements in 2012 were carried out earlier during the growth season to capture a more homogeneous set of leaves and tillers and to better fit with the timing of preliminary measurements in 2011 that had indicated significant differences in photosynthetic performance between check clones. In combination with improved stratification of our sampling effort, the timing of sampling in 2012 resulted in decreased P-values for comparisons of $A$ and $g_{s}$ between Alamo-AP13 and Kanlow-398209. Thus, our results provide some support for greater differences between these lowland cultivars during the early phases of the growing season and complement other demonstrations of seasonal variation in performance among switchgrass cultivars [33, 39].

\section{Conclusions}

We were able to detect QTL for leaf physiological performance in a lowland switchgrass 
$602 \mathrm{~F}_{1}$ despite low estimates of heritability. This demonstrates that individual lowland switchgrass 603 plants harbor genetic variability for physiological performance. Our findings also support the 604 important insight that, in addition to careful experimental control for abiotic effects, $\mathrm{G} \times \mathrm{E}$ can be 605 a crucial influence on QTL detection for physiological traits. Heritable variation in leaf structure 606 and function in switchgrass should therefore be considered when breeding for bioenergy.

607 Evidence suggests that leaf traits are often under independent genetic control, and that

608 coordinated trait variation linked with adaptation to local conditions, as demonstrated at the 609 intraspecific level in switchgrass [39], is generated by the influence of natural selection on trait 610 combinations [27]. In a crop improvement setting there is, therefore, potential for selection of 611 novel combinations of leaf traits that could complement progress in the improvement of yield 612 and biomass properties [13]. Although we found relatively few QTL for leaf phenotypes in ALB, 613 we expect that greater power to detect genetic effects in switchgrass will be obtained from 614 crosses that fully exploit known phenotypic differences linked with local adaptation $[36,45,49]$. 


\section{References}

1. U.S. Congress (2007) Energy independence and security act of 2007. Public Law 14921801. doi: papers2://publication/uuid/364DB882-E966-450B-959F-AEAD6E702F42

2. Tilman D, Socolow R, Foley JA, Hill J, Larson E, Lynd L, Pacala S, Reilly J, Searchinger T, Somerville C, Williams R (2009) Energy. Beneficial biofuels--the food, energy, and environment trilemma. Science 325:270-1. doi: 10.1126/science. 1177970

3. Searchinger T, Heimlich R, Houghton RA, Dong F, Elobeid A, Fabiosa J, Tokgoz S, Hayes D, Yu T-H (2008) Use of U.S. Croplands for Biofuels Increases Greenhouse Gases Through Emissions from Land-Use Change. Science 319:1238-1240. doi: 10.1126/science.1151861

4. Gregory PJ, George TS (2011) Feeding nine billion: the challenge to sustainable crop production. J Exp Bot 62:5233-5239. doi: 10.1093/jxb/err232

5. Denison RF (2012) Darwinian Agriculture: How Understanding Evolution Can Improve Agriculture. Princeton University Press, Princeton NJ

6. Wullschleger SD, Davis EB, Borsuk ME, Gunderson CA, Lynd LR (2010) Biomass Production in Switchgrass across the United States: Database Description and Determinants of Yield. Agron J 102:1158-1168. doi: 10.2134/agronj2010.0087

7. Behrman KD, Kiniry JR, Winchell M, Juenger TE, Keitt TH (2013) Spatial forecasting of switchgrass productivity under current and future climate change scenarios. Ecol Appl 23:73-85.

8. Gelfand I, Sahajpal R, Zhang X, Izaurralde RC, Gross KL, Robertson GP (2013) Sustainable bioenergy production from marginal lands in the US Midwest. Nature 493:514-517. doi: 10.1038/nature1 1811

9. Fargione J, Hill J, Tilman D, Polasky S, Hawthorne P (2008) Land Clearing and the Biofuel Carbon Debt. Science 319:1235-1238. doi: 10.1126/science.1152747

10. Heaton EA, Dohleman FG, Long SP (2008) Meeting US biofuel goals with less land: the potential of Miscanthus. Glob Chang Biol 14:2000-2014. doi: 10.1111/j.13652486.2008.01662.x

11. Sanderson MA, Adler PR, Boateng AA, Casler MD, Sarath G (2006) Switchgrass as a biofuels feedstock in the USA. Can J Plant Sci 86:1315-1325. doi: 10.4141/P06-136

12. Casler MD, Tobias CM, Kaeppler SM, Buell CR, Wang Z-Y, Cao P, Schmutz J, Ronald P (2011) The Switchgrass Genome: Tools and Strategies. Plant Genome 4:273. doi: 10.3835/plantgenome2011.10.0026

13. Vogel KP, Mitchell RB, Casler MD, Sarath G (2014) Registration of "Liberty" Switchgrass. J Plant Regist 8:242. doi: 10.3198/jpr2013.12.0076crc

14. Cassida KA, Muir JP, Hussey MA, Read JC, Venuto BC, Ocumpaugh WR (2005) Biomass Yield and Stand Characteristics of Switchgrass in South Central U.S. Environments. Crop Sci 45:673. doi: 10.2135/cropsci2005.0673

15. Lemus R, Brummer EC, Moore KJ, Molstad NE, Burras CL, Barker MF (2002) Biomass yield and quality of 20 switchgrass populations in southern Iowa, USA. Biomass and Bioenergy 23:433-442.

16. Dohleman FG, Heaton EA, Leakey ADB, Long SP (2009) Does greater leaf-level photosynthesis explain the larger solar energy conversion efficiency of Miscanthus relative to switchgrass? Plant, Cell Environ 32:1525-37. doi: 10.1111/j.1365-3040.2009.02017.x 
17. Zegada-Lizarazu W, Wullschleger SD, Nair SS, Monti A (2012) Crop Physiology. In: Monti A (ed) Switchgrass a valuable biomass crop for energy. Springer-Verlag, London, pp 55-86.

18. Kiniry JR, Lynd L, Greene N, Johnson M-V V, Casler MD, Laser MS (2008) Biofuels and water use: comparison of maize and switchgrass and general perspectives. In: Wright JH, Evans DA (eds) New research on biofuels. Nova Science Publishers Inc., New-York, pp 1730.

19. Long SP, Farage PK, Garcia RL (2009) Measurement of leaf and canopy photosynthetic C02 exchange in the field. J Exp Bot 47:1629-1642.

20. Maxwell K, Johnson GN (2000) Chlorophyll fluorescence--a practical guide. J Exp Bot 51:659-68.

21. Farquhar GD, von Caemmerer S, Berry JA (2001) Models of photosynthesis. Plant Physiol 125:42-5.

22. Wright IJ, Reich PB, Westoby M, Ackerly DD, Baruch Z, Bongers F, Cavender-Bares J, Chapin T, Cornelissen JHC, Diemer M, Flexas J, Garnier E, Groom PK, Gulias J, Hikosaka K, Lamont BB, Lee T, Lee W, Lusk C, Midgley JJ, Navas M-L, Niinemets Ü, Oleksyn J, Osada N, Poorter H, Poot P, Prior L, Pyankov VI, Roumet C, Thomas SC, Tjoelker MG, Veneklaas EJ, Villar R (2004) The worldwide leaf economics spectrum. Nature 428:821-7. doi: 10.1038/nature02403

23. Osnas JLD, Lichstein JW, Reich PB, Pacala SW (2013) Global leaf trait relationships: mass, area, and the leaf economics spectrum. Science 340:741-4. doi: 10.1126/science.1231574

24. Raschke K (1975) Stomatal action. Annu Rev Plant Physiol 26:309-340.

25. Jones HG (2014) Plants and microclimate: a quantitative approach to environmental plant physiology, $3^{\text {rd }}$ Edn. Cambridge University Press, Cambridge, United Kingdom

26. Nobel PS (2009) Physicochemical and Environmental Plant Physiology, 4th Edn. Academic Press, Oxford, United Kingdom

27. Donovan LA, Maherali H, Caruso CM, Huber H, de Kroon H (2011) The evolution of the worldwide leaf economics spectrum. Trends Ecol Evol 26:88-95. doi: 10.1016/j.tree.2010.11.011

28. Richards RA, Rebetzke GJ, Condon AG, van Herwaarden AF (2002) Breeding opportunities for increasing the efficiency of water use and crop yield in temperate cereal. Crop Sci 42:111-121.

29. Condon AG, Richards RA, Rebetzke GJ, Farquhar GD (2002) Improving Intrinsic WaterUse Efficiency and Crop Yield. Crop Sci 42:122-131.

30. Donovan LA, Mason CM, Bowsher AW, Goolsby EW, Ishibashi CDA (2014) Ecological and evolutionary lability of plant traits affecting carbon and nutrient cycling. $\mathrm{J}$ Ecol 102:302-314. doi: 10.1111/1365-2745.12193

31. Mason CM, Goolsby EW, Humphreys DP, Donovan LA (2015) Phylogenetic structural equation modelling reveals no need for an "origin" of the leaf economics spectrum. Ecol Lett 19:54-61. doi: 10.1111/ele.12542

32. Warner DA, Ku MSB, Edwards GE (1987) Photosynthesis, leaf anatomy, and cellular constituents in the polyploid $\mathrm{C}_{4}$ grass Panicum virgatum. Plant Physiol 84:461-466.

33. Wullschleger SD, Sanderson MA, McLaughlin SB, Biradar DP, Rayburn AL (1996) Photosynthetic Rates and Ploidy Levels among Populations of Switchgrass. Crop Sci 36:306-312. 
34. Porter Jr CL (1966) An analysis of variation between upland and lowland switchgrass, Panicum virgatum L., in central Oklahoma. Ecology 47:980-992.

35. McMillan C (1959) The role of ecotypic variation in the distribution of the central grassland of North America. Ecol Monogr 29:286-308.

36. Lowry DB, Behrman KD, Grabowski P, Morris GP, Kiniry JR, Juenger TE (2014) Adaptations between ecotypes and along environmental gradients in Panicum virgatum. Am Nat 183:682-692. doi: 10.1086/675760

37. Casler MD, Vogel KP, Taliaferro CM, Wynia RL (2004) Latitudinal Adaptation of Switchgrass Populations. Crop Sci 44:293-303.

38. Casler MD (2005) Ecotypic Variation among Switchgrass Populations from the Northern USA. Crop Sci 45:388-398.

39. Aspinwall MJ, Lowry DB, Taylor SH, Juenger TE, Hawkes C V, Johnson M V, Kiniry JR, Fay PA (2013) Genotypic variation in traits linked to climate and aboveground productivity in a widespread $\mathrm{C}_{4}$ grass: evidence for a functional trait syndrome. New Phytol 199:966980. doi: 10.1111/nph.12341

40. Hartman JC, Nippert JB, Springer CJ (2012) Ecotypic responses of switchgrass to altered precipitation. Funct Plant Biol 39:126-136.

41. Casler MD (2012) Switchgrass breeding, genetics, and genomics. In: Monti A (ed) Switchgrass a valuable biomass crop for energy. Springer-Verlag, London, pp 29-53

42. Fiedler JD, Lanzatella CL, Okada M, Jenkins J, Schmutz J, Tobias CM (2015) High-density SNP Linkage Map of Lowland Switchgrass Using Genotyping by Sequencing. Plant Genome 8. doi: 10.3835/plantgenome2014.10.0065

43. Li G, Serba DD, Saha MC, Bouton JH, Lanzatella CL, Tobias CM (2014) Genetic Linkage Mapping and Transmission Ratio Distortion in a Three-Generation Four-Founder Population of Panicum virgatum (L.). G3: Genes, Genomes, Genet 4:913-23. doi: $10.1534 / \mathrm{g} 3.113 .010165$

44. Liu L, Wu Y, Wang Y, Samuels T (2012) A High-Density Simple Sequence Repeat-Based Genetic Linkage Map of Switchgrass. G3: Genes, Genomes, Genet 2:357-370. doi: $10.1534 / \mathrm{g} 3.111 .001503$

45. Milano ER (2015) The Genetic Architecture of Quantitative Traits in Locally Adapted Plant Ecotypes. Dissertation, University of Texas at Austin

46. Missaoui AM, Paterson AH, Bouton JH (2005) Investigation of genomic organization in switchgrass (Panicum virgatum L.) using DNA markers. Theor Appl Genet 110:1372-1383.

47. Okada M, Lanzatella C, Saha MC, Bouton J, Wu R, Tobias CM (2010) Complete switchgrass genetic maps reveal subgenome collinearity, preferential pairing and multilocus interactions. Genetics 185:745-60. doi: 10.1534/genetics.110.113910

48. Serba DD, Daverdin G, Bouton JH, Devos KM, Brummer EC, Saha MC (2014) Quantitative Trait Loci (QTL) Underlying Biomass Yield and Plant Height in Switchgrass. BioEnergy Res doi: 10.1007/s12155-014-9523-8

49. Lowry DB, Taylor SH, Bonnette J, Aspinwall MJ, Asmus AL, Keitt TH, Tobias CM, Juenger TE (2015) QTLs for Biomass and Developmental Traits in Switchgrass (Panicum virgatum). BioEnergy Res doi: 10.1007/s12155-015-9629-7

50. Dong H, Thames S, Liu L, Smith MW, Yan L, Wu Y (2015) QTL Mapping for Reproductive Maturity in Lowland Switchgrass Populations. BioEnergy Res 8:1925-1937. 
doi: $10.1007 / \mathrm{s} 12155-015-9651-9$

51. Abràmoff MD, Magalhães PJ, Ram SJ (2004) Image processing with ImageJ. Biophotonics Int 11:36-41. doi: 10.1117/1.3589100

52. Pinheiro J, Bates D, DebRoy S, Sarkar D, R Core Team (2015) nlme: Linear and Nonlinear Mixed Effects Models. Version 3.1-120. http://cran.r-project.org/package=nlme. Accessed 21 March 2016

53. Kuhn M, Weston S, Wing J, Forester J, Thaler T (2013) contrast: A collection of contrast methods. Version 0.19. http://cran.r-project.org/package=contrast. Accessed 21 March 2016

54. Broman KW, Wu H, Sen S, Churchill GA (2003) R/qtl: QTL mapping in experimental crosses. Bioinformatics 19:889-890.

55. Margarido GRA, Souza AP, Garcia AAF (2007) OneMap: software for genetic mapping in outcrossing species. Hereditas 144:78-79.

56. Maseda PH, Fernández RJ (2006) Stay wet or else: three ways in which plants can adjust hydraulically to their environment. J Exp Bot 57:3963-77. doi: 10.1093/jxb/erl127

57. Serba D, Wu L, Daverdin G, Bahri BA, Wang X, Kilian A, Bouton JH, Brummer EC, Saha MC, Devos KM (2013) Linkage Maps of Lowland and Upland Tetraploid Switchgrass Ecotypes. Bioenergy Res 6:953-965. doi: 10.1007/s12155-013-9315-6

58. Lowry DB, Hernandez K, Taylor SH, Meyer E, Logan TL, Barry K, Chapman J, Rokhsar DS, Schmutz J, Juenger TE (2015) The Genetics of Divergence and Reproductive Isolation Between Ecotypes of Panicum hallii. New Phytol 205:402-414. doi: 10.1111/nph.13027

59. Condon AG, Richards RA, Rebetzke GJ, Farquhar GD (2004) Breeding for high water-use efficiency. J Exp Bot 55:2447-2460. doi: 10.1093/jxb/erh277

60. Campitelli BE, Des Marais DL, Juenger TE (2016) Ecological interactions and the fitness effect of water-use efficiency: Competition and drought alter the impact of natural MPK12 alleles in Arabidopsis. Ecol Lett 19:424-434 doi: 10.1111/ele.12575

61. Liu Y, Zhang X, Tran H, Shan L, Kim J, Childs K, Ervin EH, Frazier T, Zhao B (2015) Assessment of drought tolerance of 49 switchgrass (Panicum virgatum) genotypes using physiological and morphological parameters. Biotechnol Biofuels 8:1-18. doi: 10.1186/s13068-015-0342-8

62. Demmig-Adams B, Adams WW (2006) Photoprotection in an ecological context: The remarkable complexity of thermal energy dissipation. New Phytol 172:11-21. doi: $10.1111 / j .1469-8137.2006 .01835 . x$

63. Heckathorn SA, DeLucia EH (1991) Effect of Leaf Rolling on Gas Exchange and Leaf Temperature of Andropogon gerardii and Spartina pectinata. Bot Gaz 152:263. doi: $10.1086 / 337888$

64. Redmann RE (1985) Adaptation of Grasses to Water Stress-Leaf Rolling and Stomate Distribution. Ann Missouri Bot Gard 72:833-842.

65. O'Toole JC, Cruz RT (1980) Response of leaf water potential, stomatal resistance, and leaf rolling to water stress. Plant Physiol 65:428-32. 
787 Table 1 P-values testing for genetic and environmental effects on leaf phenotypes of switchgrass clones 788 regularly interspersed in 'even' and 'odd' replicates of the ALB $F_{1}$ switchgrass population growing in 789 Austin, Texas.

\begin{tabular}{|c|c|c|c|c|c|}
\hline${ }^{1}$ Experiment & Phenotype & ${ }^{2}$ Genotype & ${ }^{2}$ Environment & ${ }^{2}$ Genotype $\times$ Environment & ${ }^{3}$ Autocorrelation \\
\hline \multirow[t]{9}{*}{ A } & Mass & 0.007 & 0.06 & 0.373 & 0.0004 \\
\hline & Area & 0.032 & 0.066 & 0.444 & $<0.0001$ \\
\hline & LMA & $<0.0001$ & 0.41 & 0.637 & 0.088 \\
\hline & $A$ & 0.149 & 0.203 & 0.552 & 0.978 \\
\hline & $g_{s}$ & 0.185 & 0.521 & 0.921 & 0.999 \\
\hline & $i W U E$ & 0.230 & 0.985 & 0.324 & 0.576 \\
\hline & $\Phi_{\text {PSII }}$ & 0.087 & 0.263 & 0.143 & 0.998 \\
\hline & $\mathrm{F}_{\mathrm{v}}^{\prime} / \mathrm{F}_{\mathrm{m}}{ }^{\prime}$ & 0.008 & 0.238 & 0.37 & 0.999 \\
\hline & $\mathrm{q}_{\mathrm{P}}$ & 0.293 & 0.338 & 0.074 & 0.792 \\
\hline \multirow[t]{7}{*}{ B } & $A$ & 0.128 & $\mid<0.0001$ & 0.054 & 0.028 \\
\hline & $g_{s}$ & 0.107 & $\mid<\mathbf{0 . 0 0 0 1}$ & 0.082 & 0.093 \\
\hline & $i W U E$ & 0.147 & 0.273 & 0.276 & 0.703 \\
\hline & $\Phi_{\text {PSII }}$ & 0.005 & $\mid<0.0001$ & 0.046 & 0.015 \\
\hline & $\mathrm{F}_{\mathrm{v}}^{\prime} / \mathrm{F}_{\mathrm{m}}{ }^{\prime}$ & $<0.0001$ & 0.0002 & 0.281 & 0.654 \\
\hline & $\mathrm{qP}_{\mathrm{P}}$ & 0.367 & $\mid<\mathbf{0 . 0 0 0 1}$ & 0.054 & 0.0005 \\
\hline & $\Psi_{\mathrm{m}}$ & 0.194 & $\mid<\mathbf{0 . 0 0 0 1}$ & 0.693 & $<0.0001$ \\
\hline \multirow[t]{8}{*}{$\mathrm{C}$} & Mass & 0.147 & 0.638 & 0.187 & 0.219 \\
\hline & Area & 0.033 & 0.737 & 0.274 & 0.036 \\
\hline & LMA & 0.019 & 0.011 & 0.391 & 0.021 \\
\hline & $A$ & 0.058 & 0.015 & 0.528 & 0.999 \\
\hline & $g_{s}$ & 0.051 & 0.014 & 0.164 & 0.999 \\
\hline & $i W U E$ & 0.698 & 0.229 & 0.437 & 0.999 \\
\hline & $\Delta \Psi$ & 0.201 & 0.03 & 0.121 & 0.210 \\
\hline & $\Psi_{\mathrm{m}}$ & 0.826 & 0.067 & 0.308 & 0.392 \\
\hline
\end{tabular}

${ }^{1}$ Experiments: A, odd and even replicates watered July 2011; B, even replicate watered and odd replicate droughted July 2011; C, odd and even replicates watered May 2012

${ }^{2}$ Wald tests $\left(\right.$ all $\left.\mathrm{F}_{1,58}\right)$ : Genotype, Alamo-AP13 vs. Kanlow-398209; Environment, even vs. odd ${ }^{3}$ Likelihood ratio tests $\left(\chi^{2} 1\right)$

Values in bold are statistically significant 
Table 2 Similarity between clonal replicates (correlation, Pearson's $\rho$ ) for phenotypes measured 791 from $165 \mathrm{~F}_{1}$ lowland switchgrass genotypes in the ALB mapping population, and the impact of using normalized residuals to correct for experimental effects (day, observer and spatial correlation).

\begin{tabular}{|c|c|c|c|c|c|c|}
\hline \multirow[b]{2}{*}{ Phenotype } & \multicolumn{2}{|c|}{$\begin{array}{l}\text { Experiment A } \\
\text { June } 2011\end{array}$} & \multicolumn{2}{|c|}{$\begin{array}{l}\text { Experiment B } \\
\text { June } 2011\end{array}$} & \multicolumn{2}{|c|}{$\begin{array}{c}\text { Experiment C } \\
\text { May } 2012\end{array}$} \\
\hline & $\rho$ & Corrected $\rho$ & $\rho$ & Corrected $\rho$ & $\rho$ & Corrected $\rho$ \\
\hline Mass & 0.12 & $0.24 * * *$ & - & - & $0.35 * * *$ & $0.35 * * *$ \\
\hline Area & 0.08 & $0.22 * *$ & - & - & $0.25 * * *$ & $0.28 * * *$ \\
\hline LMA & $0.31 * * *$ & $0.33 * * *$ & - & - & $0.18 * *$ & $0.22 * *$ \\
\hline$A$ & 0.12 & $0.16 *$ & 0.10 & 0.12 & 0.04 & $0.15 *$ \\
\hline$g_{s}$ & 0.11 & $0.17 *$ & 0.09 & $0.16 *$ & 0.07 & $0.14 *$ \\
\hline$i W U E$ & 0.04 & 0.03 & 0.01 & 0.02 & $0.13 *$ & $0.14 *$ \\
\hline $\mathrm{F}_{\mathrm{v}}{ }^{\prime} / \mathrm{F}_{\mathrm{m}}{ }^{\prime}$ & 0.05 & 0.06 & 0.07 & 0.10 & - & - \\
\hline$\Phi_{\text {PSII }}$ & 0.01 & 0.06 & $0.14 *$ & $0.16 *$ & - & - \\
\hline $\mathrm{q}_{\mathrm{P}}$ & 0.06 & 0.09 & 0.12 & 0.11 & - & - \\
\hline$\Delta \Psi$ & - & - & - & - & 0.04 & 0.04 \\
\hline$\Psi_{\mathrm{m}}$ & - & - & -0.05 & 0.08 & 0.05 & 0.07 \\
\hline
\end{tabular}


795 Table 3 Significance and magnitude of experimental design factors and spatial correlations affecting leaf phenotypes of 165 ALB $F_{1}$ switchgrass genotypes grown in Austin, Texas.

\begin{tabular}{|c|c|c|c|c|c|c|c|}
\hline \multirow[b]{2}{*}{${ }^{1}$ Experiment } & \multirow[b]{2}{*}{ Phenotype } & \multirow{2}{*}{\begin{tabular}{|l|}
${ }^{2}$ Odd vs. Even \\
P-values
\end{tabular}} & \multicolumn{2}{|l|}{${ }^{2}$ Observer } & \multicolumn{2}{|l|}{${ }^{2}$ Day } & \multirow{2}{*}{\begin{tabular}{|l|}
${ }^{3}$ Autocorrelation \\
P-values
\end{tabular}} \\
\hline & & & P-values & $\begin{array}{l}\text { Range of means/ } \\
\text { grand mean }(\%)\end{array}$ & P-values & $\begin{array}{l}\text { Range of means/ } \\
\text { grand mean }(\%)\end{array}$ & \\
\hline \multirow[t]{9}{*}{ A } & Mass & 0.553 & - & - & 0.919 & 6.4 & $<0.0001$ \\
\hline & Area & 0.842 & - & - & 0.852 & 9.6 & $<0.0001$ \\
\hline & LMA & 0.354 & - & - & 0.011 & 5 & 0.933 \\
\hline & $A$ & 0.060 & 0.011 & 18.9 & $<0.0001$ & 23.2 & 0.107 \\
\hline & $g_{s}$ & 0.4 & 0.199 & 15.1 & $<0.0001$ & 32.8 & 0.0002 \\
\hline & $i W U E$ & 0.027 & 0.0008 & 8 & $<0.0001$ & 10.4 & 0.0002 \\
\hline & $\mathrm{F}_{\mathrm{v}}^{\prime} / \mathrm{F}_{\mathrm{m}}{ }^{\prime}$ & 0.004 & $<0.0001$ & 8.4 & $<0.0001$ & 8.7 & 0.002 \\
\hline & $\Phi_{\text {PSII }}$ & 0.064 & 0.0009 & 14.1 & $<0.0001$ & 18.2 & 0.182 \\
\hline & $\mathrm{q}_{\mathrm{P}}$ & 0.428 & 0.0007 & 11.5 & 0.0001 & 9.9 & 0.303 \\
\hline \multirow[t]{7}{*}{ B } & $A$ & $<0.0001$ & 0.426 & 55.9 & $<0.0001$ & 27.8 & $<0.0001$ \\
\hline & $g_{s}$ & $<0.0001$ & 0.092 & 59.7 & $<0.0001$ & 35.1 & 0.0003 \\
\hline & $i W U E$ & 0.0002 & 0.009 & 3.4 & 0.344 & 4 & 0.199 \\
\hline & $\mathrm{F}_{\mathrm{v}}^{\prime} / \mathrm{F}_{\mathrm{m}}{ }^{\prime}$ & $<0.0001$ & $<0.0001$ & 5.5 & 0.0007 & 8.7 & 0.003 \\
\hline & $\Phi_{\mathrm{PSII}}$ & $<0.0001$ & 0.119 & 30.7 & $<0.0001$ & 27.2 & 0.051 \\
\hline & $\mathrm{q}_{\mathrm{P}}$ & $<0.0001$ & 0.39 & 25.3 & $<0.0001$ & 19.2 & 0.052 \\
\hline & $\Psi_{\mathrm{m}}$ & $<0.0001$ & 0.0008 & 6.4 & 0.004 & 10.6 & $<0.0001$ \\
\hline \multirow[t]{8}{*}{$\mathrm{C}$ - even } & Mass & - & - & - & 0.934 & 0.4 & 0.75 \\
\hline & Area & - & - & - & 0.082 & 11.3 & $<0.0001$ \\
\hline & LMA & - & - & - & 0.088 & 4.6 & $<0.0001$ \\
\hline & $A$ & - & $<0.0001$ & 23.5 & 0.084 & 4.6 & 0.745 \\
\hline & $g_{s}$ & . & 0.047 & 18.5 & 0.046 & 9.5 & 0.226 \\
\hline & $i W U E$ & - & 0.005 & 13 & 0.046 & 5.4 & 0.057 \\
\hline & $\dagger \Delta \Psi$ & - & 0.988 & 0.1 & 0.306 & 3.7 & 0.003 \\
\hline & $\dagger \Psi_{m}$ & . & 0.422 & 2.7 & 0.172 & 4.4 & 0.004 \\
\hline \multirow[t]{8}{*}{ C - odd } & Mass & - & - & - & 0.136 & 7.6 & 0.129 \\
\hline & Area & - & - & - & 0.024 & 12.7 & 0.01 \\
\hline & LMA & - & - & - & 0.026 & 7.4 & $<0.0001$ \\
\hline & $A$ & - & $<0.0001$ & 30.3 & 0.234 & 5.5 & 0.13 \\
\hline & $g_{s}$ & . & 0.002 & 33.3 & 0.256 & 7.2 & 0.07 \\
\hline & $i W U E$ & - & 0.031 & 12.7 & $<0.0001$ & 13.5 & 0.217 \\
\hline & $\dagger \Delta \Psi$ & - & 0.762 & 1.2 & 0.379 & 3.5 & 0.0009 \\
\hline & $\dagger \Psi_{m}$ & . & 0.508 & 2.2 & 0.785 & 0.9 & 0.005 \\
\hline
\end{tabular}

${ }^{1}$ Experiment A, July 2011 odd and even replicates watered; Experiment B, July 2011 even replicate watered and odd replicate droughted; Experiment $\mathrm{C}$, odd and even replicates watered similarly but measured consecutively and tested independently.

${ }^{2}$ Wald F-tests, numerator d.f.: Odd vs. Even $=1$; Observer $=3$, except $\Psi_{\mathrm{m}}$ and $\Delta \Psi=1$; Day Experiments A \& B $=3$, Day Experiment $\mathrm{C}=1$.

${ }^{3}$ Likelihood ratio tests $\left(\chi_{1}^{2}\right)$

Values in bold are statistically significant 

even rows) using phenotypes corrected for additive experimental effects (odd-even, day of experiment, where relevant observer) 800 and spatial autocorrelation, i.e., normalized residuals; QTL with $\mathrm{P}<0.1$ based on permutation testing are shown by experiment 801 and linkage group (LG).

\begin{tabular}{|c|c|c|c|c|c|c|c|c|}
\hline Experiment ${ }^{1}$ & LG & Replicate & Phenotype & Position (cM) & 1.5 LOD interval (cM) & Marker $^{2}$ & $\mathrm{LOD}^{3}$ & $\begin{array}{l}\text { Percent variation } \\
\text { explained }\end{array}$ \\
\hline \multirow[t]{4}{*}{ A } & $2 b$ & even & $g_{s}$ & 52.8 & $0-66$ & sww1517 & $4.06^{+}$ & 10.77 \\
\hline & $5 b$ & even & ФPSII & 32.0 & $0-72$ & - & $4^{+}$ & 10.63 \\
\hline & $5 b$ & even & qP & 48.2 & $2-72$ & sww1252 & $4.62 *$ & 12.16 \\
\hline & $5 b$ & odd & LMA & 146.0 & $134-147$ & - & $5.14 *$ & 13.43 \\
\hline \multirow[t]{2}{*}{ B } & $3 a$ & even & $g_{s}$ & 87.2 & $66-121$ & sww2747 & $3.93^{+}$ & 10.44 \\
\hline & $9 \mathrm{a}$ & odd (dry) & iWUE & 55.2 & $24.0-96$ & nfsg107 & $4.66^{*}$ & 12.26 \\
\hline \multirow[t]{3}{*}{$\mathrm{C}$} & $1 \mathrm{~b}$ & even & mass & 34 & $24-62$ & sww2596 & $5.43 * *$ & 14.13 \\
\hline & $1 \mathrm{~b}$ & even & area & 41.3 & $24-73.9$ & sww1855 & $4.07^{+}$ & 10.8 \\
\hline & $1 \mathrm{~b}$ & odd & mass & 45.7 & $22-66$ & sww2970 & $5.25 * *$ & 13.71 \\
\hline
\end{tabular}

${ }^{1}$ Experiments were: A, odd and even replicates watered July 2011; B, even replicate watered and odd replicate droughted July 2011; C, odd and even replicates watered May 2012.

${ }^{2}$ Missing values indicate localisation to a pseudomarker position.

${ }^{3+} 0.05 \leq \mathrm{P}<0.1, * 0.01 \leq \mathrm{P}<0.05, * * 0.001 \leq \mathrm{P}<0.01, * * * \mathrm{P}<0.001$ (LOD threshold ranges: $\mathrm{P}=0.1,3.8-4.09 ; \mathrm{P}=0.05,4.12-4.46 ; \mathrm{P}=0.01$, 4.73-5.58; $\mathrm{P}=0.001,5.2-7.53)$. 
803 Table 5 Single marker tests of QTL, Environment ('odd' versus 'even' replicate), and QTL $\times$ Environment effects at markers and 804 pseudomarkers corresponding to peak LOD scores in ALB

\begin{tabular}{|c|c|c|c|c|c|c|}
\hline & & & & \multicolumn{3}{|c|}{ P-values: mean $(2.5,97.5$ percentile $)$} \\
\hline Experiment & LG & ${ }^{1}$ Phenotype & $\begin{array}{l}\text { Marker/ } \\
\text { pseudomarker } \\
\text { position } \\
\text { sww1517 }\end{array}$ & $0.018(0.017,0.023)$ & $0.974(0.974,0.974)$ & $\begin{array}{l}{ }^{2} \text { Genotype } \times \\
\text { Environment } \\
\mathbf{0 . 0 4 7}(0.039,0.048)\end{array}$ \\
\hline \multirow{3}{*}{ A } & $5 b$ & $\Phi_{\text {PSII }}$ & $32 \mathrm{cM}$ & $0.382(0.029,0.862)$ & $0.887(0.886,0.888)$ & $0.308(0.012,0.807)$ \\
\hline & $5 b$ & $\mathrm{qP}_{\mathrm{P}}$ & sww1252 & $0.168(0.004,0.622)$ & $0.912(0.911,0.913)$ & $0.334(0.021,0.844)$ \\
\hline & $5 b$ & LMA & $146 \mathrm{cM}$ & $\mathbf{1} \times \mathbf{1 0}^{-4}\left(4 \times 10^{-7}, 7 \times 10^{-4}\right)$ & $0.995(0.995,0.995)$ & $0.207(0.062,0.374)$ \\
\hline \multirow[t]{2}{*}{ B } & $3 a$ & $g_{s}$ & sww2747 & $0.001\left(5 \times 10^{-4}, 0.002\right)$ & $0.795(0.795,0.796)$ & $0.071(0.053,0.096)$ \\
\hline & $9 \mathrm{a}$ & iWUE & nfsg107 & $0.013\left(4 \times 10^{-4}, 0.063\right)$ & $0.929(0.929,0931)$ & $0.005\left(1 \times 10^{-4}, 0.022\right)$ \\
\hline \multirow[t]{3}{*}{$\mathrm{C}$} & $1 \mathrm{~b}$ & mass & sww2596 & $\mathbf{4} \times \mathbf{1 0}^{-9}\left(2 \times 10^{-9}, 2 \times 10^{-8}\right)$ & $0.99(0.99,0.99)$ & $0.553(0.553,0,722)$ \\
\hline & $1 \mathrm{~b}$ & area & sww1855 & $7 \times 10^{-6}\left(1 \times 10^{-7}, 2 \times 10^{-5}\right)$ & $0.365(0.361,0.369)$ & $0.897(0.761,0.961)$ \\
\hline & $1 \mathrm{~b}$ & mass & sww2970 & $\mathbf{2} \times 10^{-5}\left(2 \times 10^{-9}, 5 \times 10^{-5}\right)$ & $0.991(0.99,0.991)$ & $0.518(0.322,0.674)$ \\
\hline
\end{tabular}

${ }^{1}$ Normalized residuals, correcting for additive experimental effects (odd-even, day of measurement, and where relevant observer) and spatial autocorrelation

${ }^{2} \mathrm{P}$-values from ANOVA applied to 500 imputed genotype classifications (marker sww2596 was fully informative and 498/500 imputed genotype sets matched exactly, so P-values are maximum and minimum not percentiles) 
806 Figure legends

807 Fig. 1 Leaf physiological phenotypes for Alamo-AP13 (filled symbols, solid line) and Kanlow808398209 (open symbols, dashed line), including response to drought (center column). Generalized 809 least squares means and standard errors $(\mathrm{N}=14-16)$ are shown for: $(\mathrm{a}, \mathrm{j}, \mathrm{q}) A$, net $\mathrm{CO}_{2}$ assimilation; (b,k,r) $g_{s}$, stomatal conductance to water; $(\mathrm{c}, 1, \mathrm{~s})$ iWUE, intrinsic water use

811 efficiency; (d,m) ФPSII, quantum efficiency of photosystem II; (e,n) $\mathrm{F}_{\mathrm{v}}{ }^{\prime} / \mathrm{F}_{\mathrm{m}}$ ', light adapted

812 efficiency of energy harvesting by open photosystem II reaction centers; (f,o) qp, photochemical 813 quenching of chlorophyll fluorescence; $(\mathrm{p}, \mathrm{t}) \Psi_{\mathrm{m}}$, midday leaf water potential; (u) $\Delta \Psi$, midday 814 hydrodynamic gradient; $(\mathrm{g}, \mathrm{v})$ leaf mass; $(\mathrm{h}, \mathrm{w})$ leaf area; (i,x) LMA, leaf mass per area.

815 Significance values for statistical tests are presented in Table 1.

816 Fig. 2 Leaf physiological phenotypes for two replicates of the ALB $F_{1}$ mapping population, 817 including response to drought (center column). Generalized least squares means and standard 818 errors $\left(\mathrm{N}=165 \mathrm{~F}_{1}\right)$ are shown for: $(\mathrm{a}, \mathrm{j}, \mathrm{q}) A$, net $\mathrm{CO}_{2}$ assimilation; $(\mathrm{b}, \mathrm{k}, \mathrm{r}) g_{s}$, stomatal 819 conductance to water; $(\mathrm{c}, 1, \mathrm{~s})$ iWUE, intrinsic water use efficiency; $(\mathrm{d}, \mathrm{m}) \Phi_{\mathrm{PSII}}$, quantum 820 efficiency of photosystem II; $(\mathrm{e}, \mathrm{n}) \mathrm{F}_{\mathrm{v}} / \mathrm{F}_{\mathrm{m}}$ ', light adapted efficiency of energy harvesting by open 821 photosystem II reaction centers; (f,o) qP, photochemical quenching of chlorophyll fluorescence; 822 (p,t) $\Psi_{\mathrm{m}}$, midday leaf water potential; (u) $\Delta \Psi$, midday hydrodynamic gradient; (g,v) leaf mass; $823(\mathrm{~h}, \mathrm{w})$ leaf area; (i,x) LMA, leaf mass per area. Significance values for statistical tests are 824 presented in Table 3.

825 Fig. 3 Linkage map for ALB [50] and locations of peak LOD scores and 1.5 LOD intervals for normalized residuals of leaf physiological phenotypes. QTL are labelled with phenotype, replicate (even or odd) and Experiment (A, odd and even replicates watered July 2011; B, odd replicate droughted and even replicate watered July 2011; C, odd and even replicates watered 830 closest to the linkage group: black indicates $\mathrm{P}<0.05$, gray $0.05 \leq \mathrm{P}<0.1$. Phenotypes: mass, leaf 831 lamina mass; area,leaf lamina area; $g_{s}$, stomatal conductance to water; $\Phi_{\text {PSII }}$, quantum efficiency 832 of photosystem II; qP, photochemical quenching; LMA, leaf lamina mass per leaf lamina area; 833 iWUE, intrinsic water use efficiency. 
835 Fig. 4 Phenotypes by genotype, at five markers linked with QTL in ALB with no support for 836 significant $\mathrm{G} \times \mathrm{E}$. Marker names shown on the $\mathrm{y}$-axis indicate the linkage group-marker837 phenotype combination. Phenotypes are plotted as clouds of normalized residuals for all $165 \mathrm{~F}_{1}$, 838 alongside means and s.e.m.; open symbols represent individuals from the 'odd' replicate, filled 839 symbols the 'even' replicate. Replicates were watered similarly except (i-j) where drought was 840 imposed on the 'odd' replicate. Parental genotypes, shown on the x-axis, were Alamo-A4 (A) and 841 Kanlow-K5 (K), subscripts indicate alleles assigned by imputation.

842 Fig. 5 Phenotypes by genotype at two markers linked with QTL in ALB where marker regression 843 supported significant $\mathrm{G} \times \mathrm{E}$. Marker names shown on the $\mathrm{y}$-axis indicate the linkage-group844 marker-phenotype combination. Phenotypes are plotted as clouds of normalized residuals for 165 $845 \mathrm{~F}_{1}$, alongside means and s.e.m.; open symbols represent the 'odd' replicate, filled symbols the 846 'even' replicate. Replicates were watered similarly in a-b, and drought was imposed on the 'odd' 847 replicate in c-d. Parental genotypes were Alamo-A4 (A) and Kanlow-K5 (K); alleles assigned by 848 imputation at each marker are indicated by subscripts. 


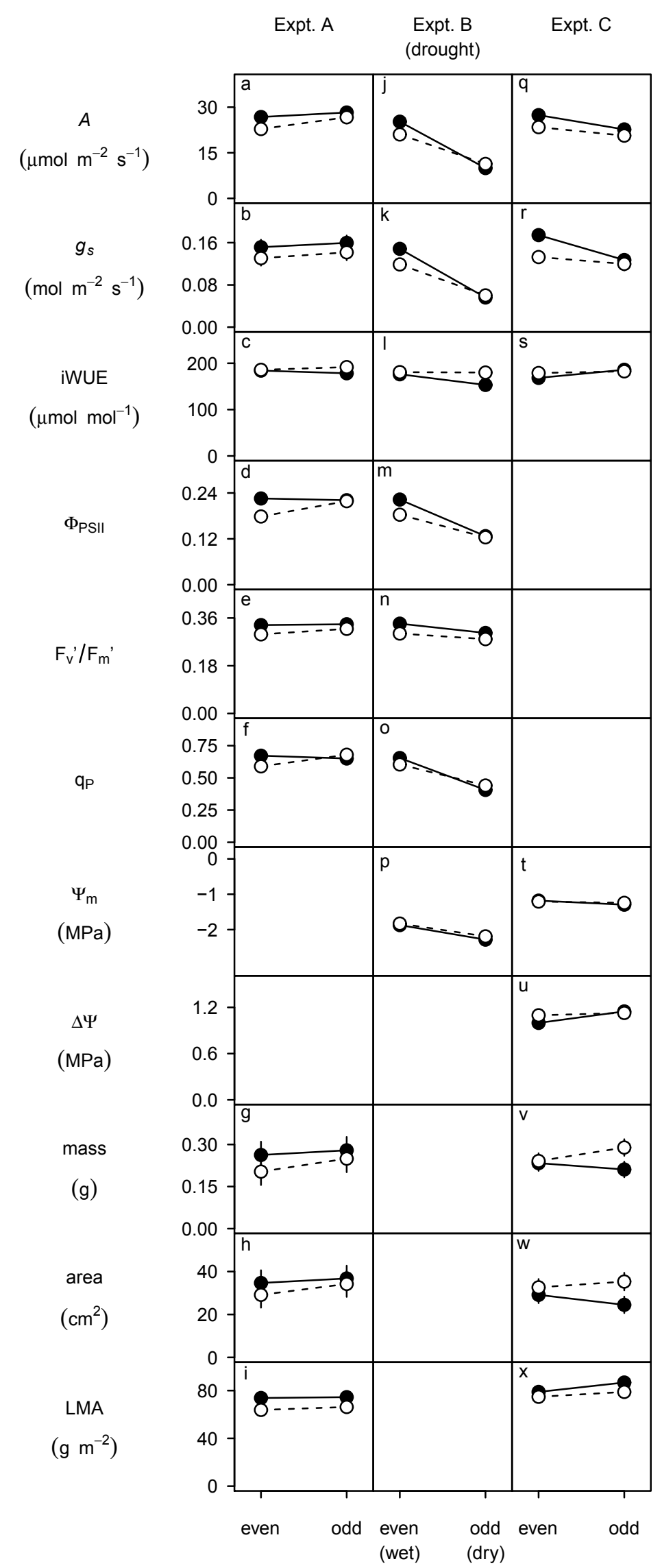




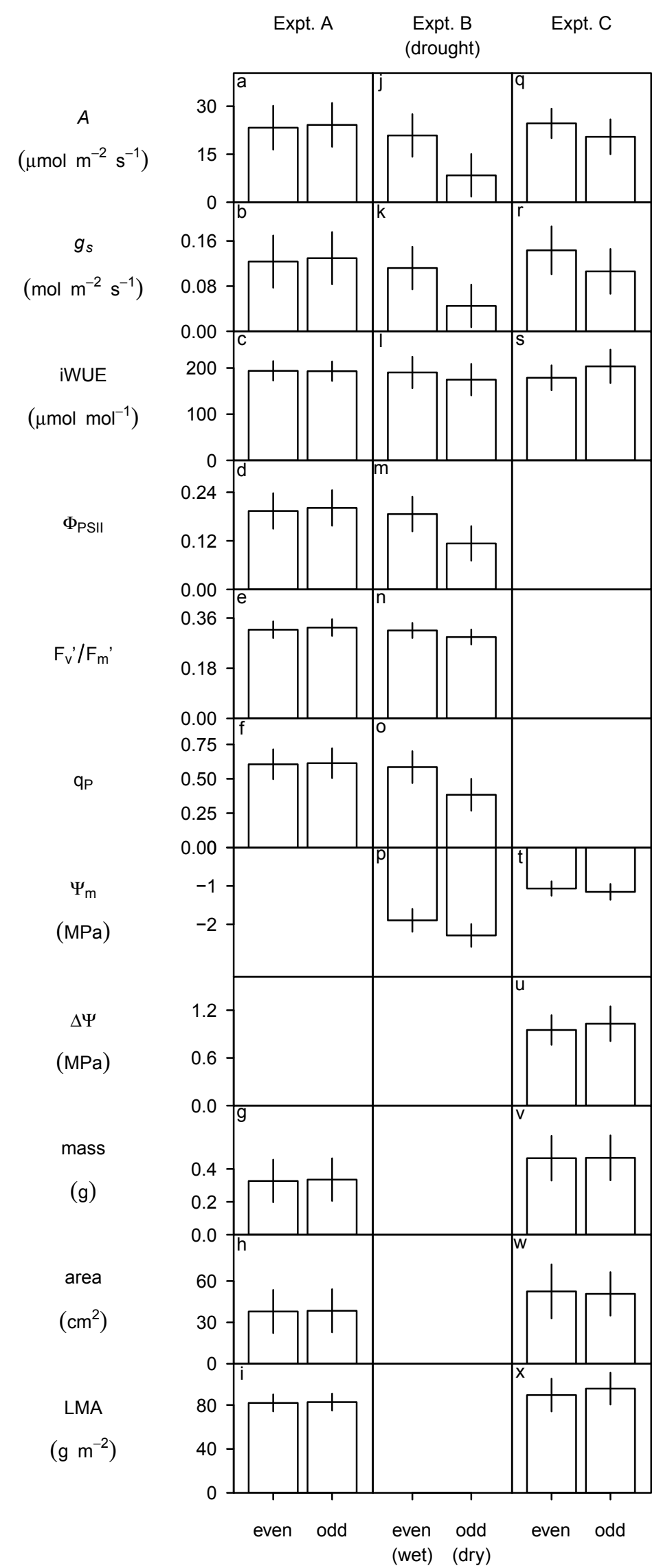


$1 a$

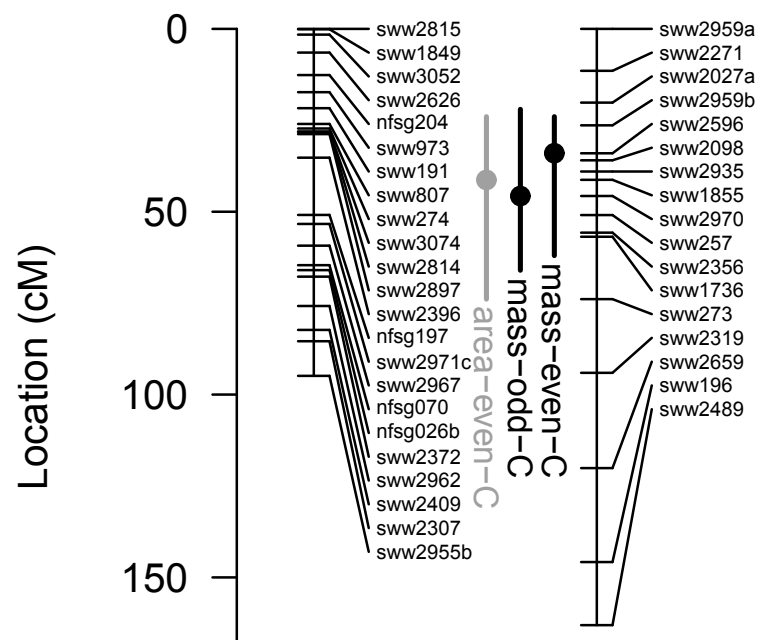

$4 a$

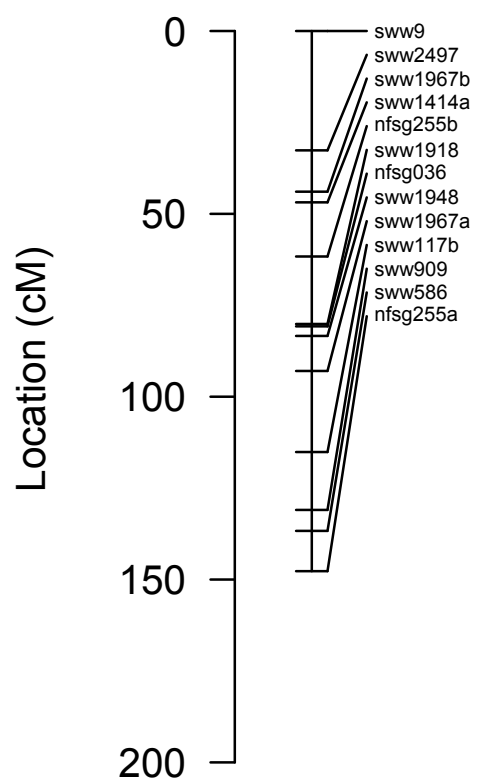

$7 a$

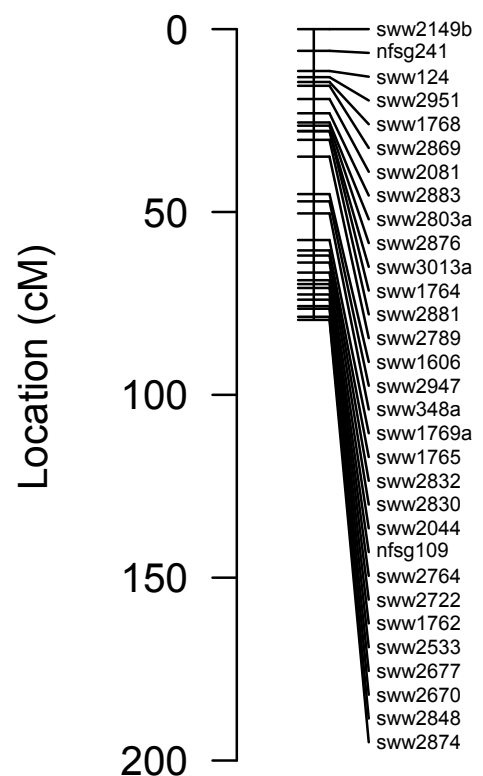

$7 b$

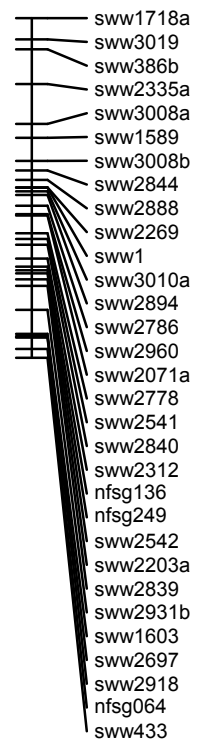

$1 b$
$2 a$

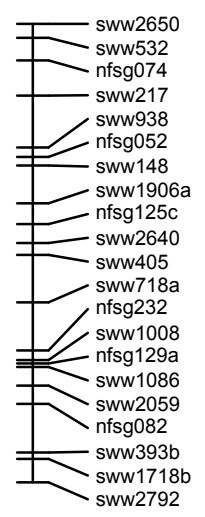

$2 b$

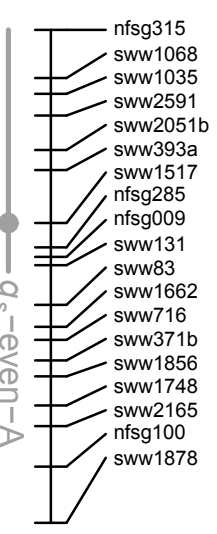

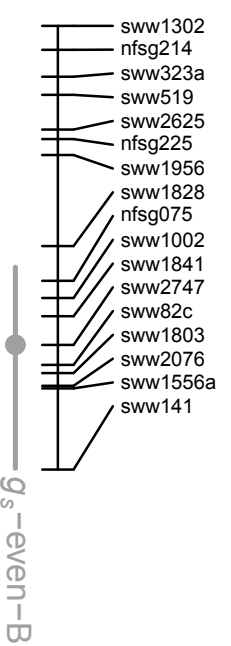

$5 a$

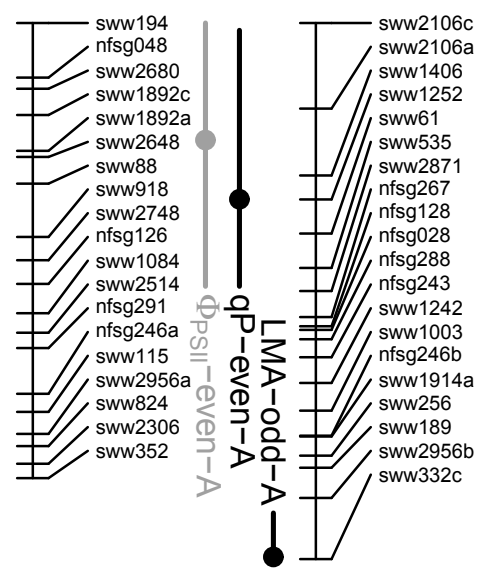

T sww705

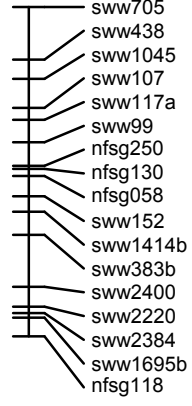

$8 b$

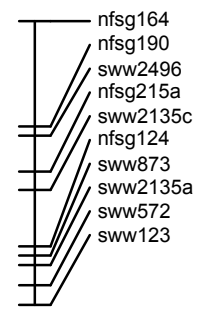

$3 a$

$3 b$

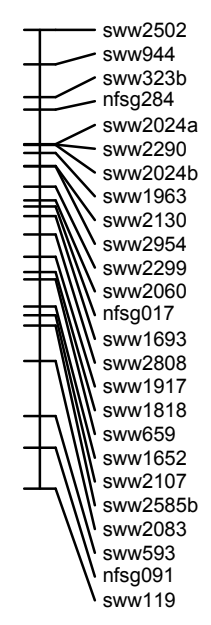

$6 b$
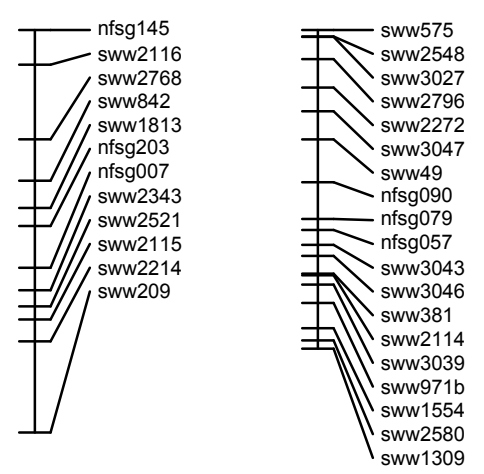

$9 a$

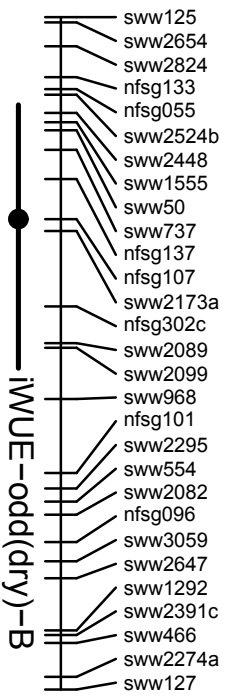

$9 b$

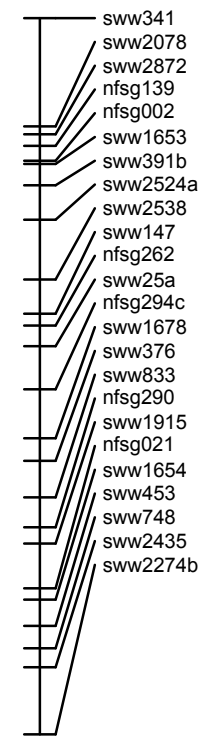




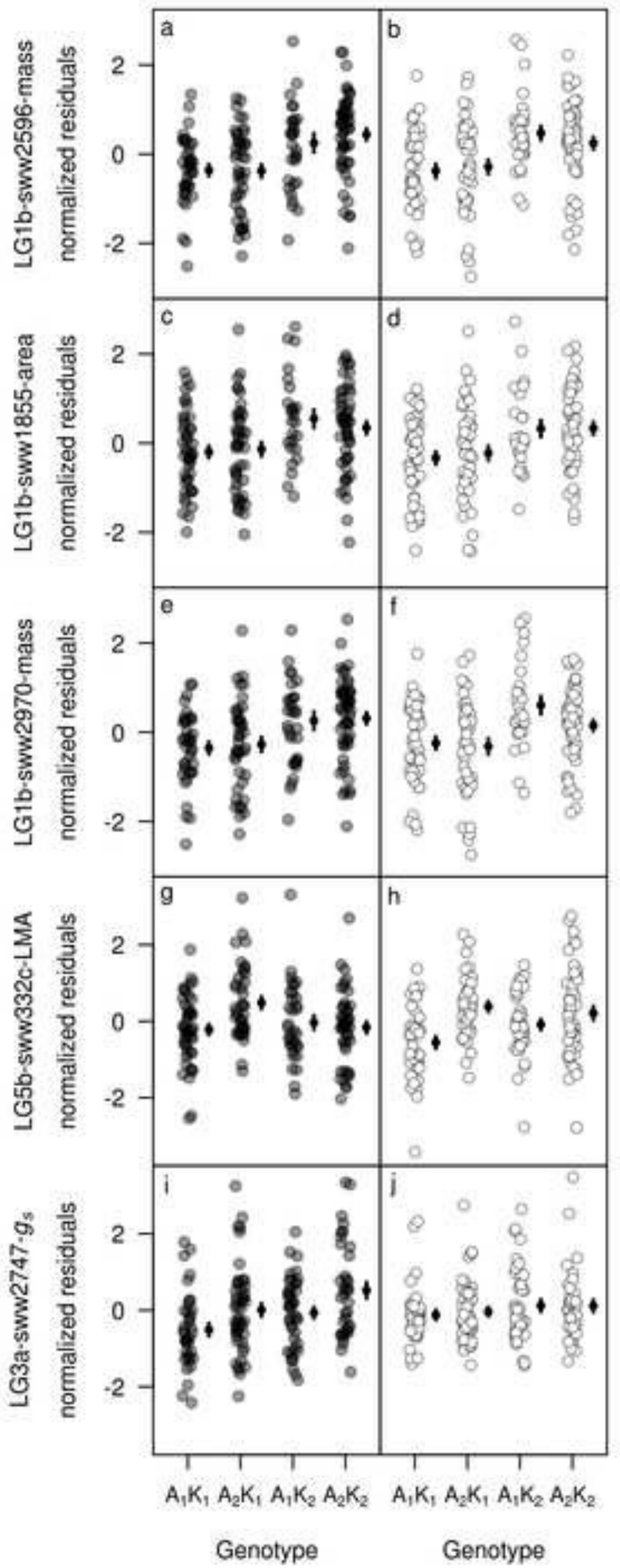




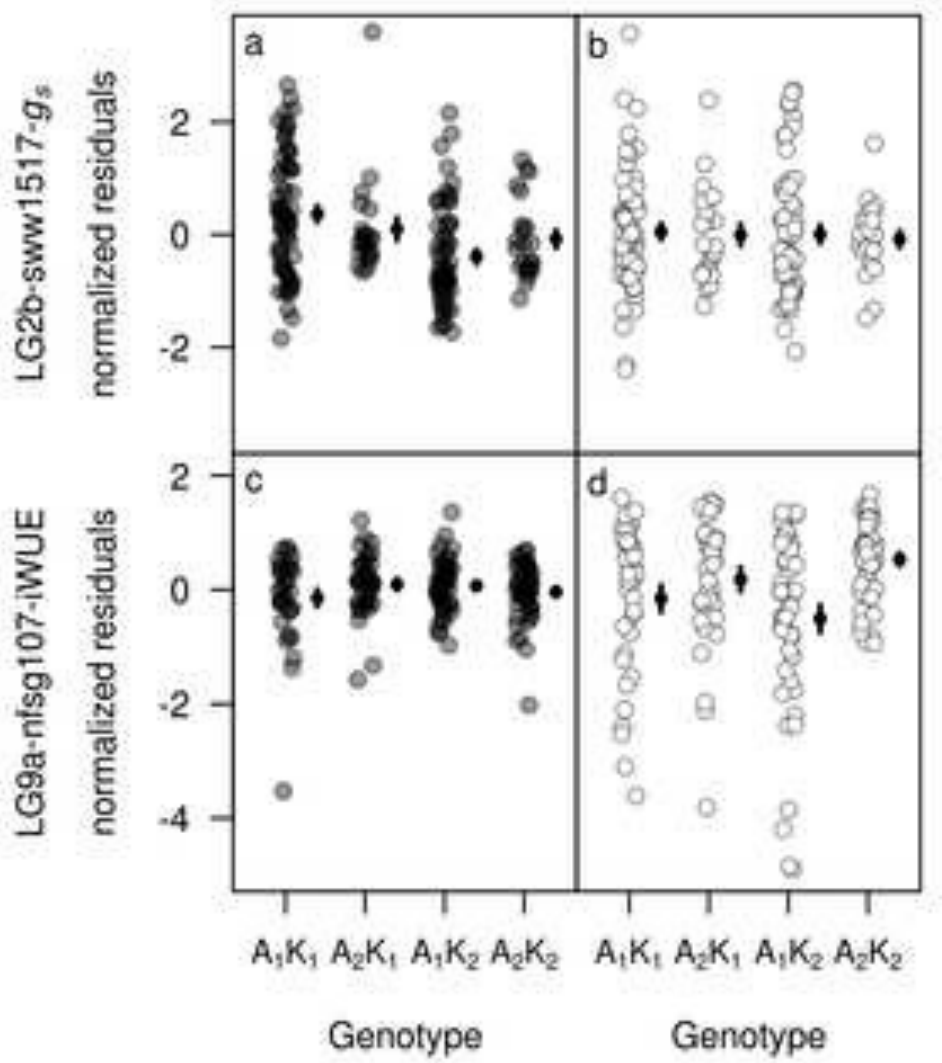

